NASA Contractor Report 3459

\title{
Satellite Measurements of Tropospheric Aerosols
}

M. Griggs

CONTRACT NAS1-15898

AUGUST 1981 
NASA Contractor Report 3459

\section{Satellite Measurements of Tropospheric Aerosols}

\section{Griggs}

Science Applications, Inc.

La Jolla, California

Prepared for

Langley Research Center

under Contract NAS1-15898

\section{N/SA \\ National Aeronautics \\ and Space Administration}

Scientific and Technical

Information Branch

1981 



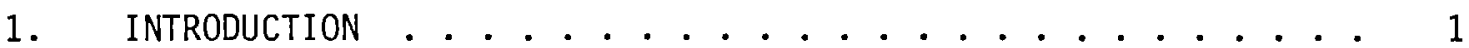

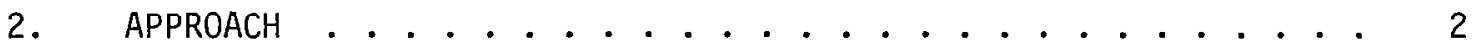

2.1 Test Sites................ 5

3. OTHER METHODS FOR SATELLITE MEASUREMENTS OF TROPOSPHERIC

AEROSOLS OVER LAND ................. . 7

3.1 Review of Potter and Mendlowitz Method . . . . . . . 8

3.2 Review of Barnes et al Method ........... 16

4. DATA ANALYSIS METHODS ................ 23

4.1 Radiance Data . . . . . . . . . . . 23

4.1.1 Sun Correction Factor ......... 23

4.1.2 Water Vapor Correction for MSS7 . . . . . 23

4.2 Sunphotometer Data ............. 27

5. RESULTS ....................... 28

5.1 Radiance Data .............. 28

5.1.1 Water Vapor Correction .......... 28

5.2 Radiance-Aerosol Content Relationship ....... 33

5.3 Error Sources .............. . 33

5.3.1 Sunphotometer Errors .......... 33

5.3.2 Radiance Errors . . . . . . . . . . 34

5.3.3 Sun-Angle Correction Factor Errors . . . . . 35

5.3.4 Water Vapor Absorption Effects . . . . . . 35

5.3.5 Effects of Aerosol Properties ....... . 36

5.3.6 Adjacency Effects ........... 36

5.3.7 Water Turbidity Effects ......... 36 
5.4 Adjacency Effects .............. . . 37

5.4 .1 Theory ............. . 37

5.4.2 Landsat Data ........... 39

5.5 A Comparison of Inland and Ocean Landsat Data . . . . . 43

5.6 Estimation of the Aerosol Content from Radiance

Measurements ............ . 53

6. CONCLUSIONS AND RECOMMENDATIONS ........... 55

7. REFERENCES .................... 57 


\section{SUMMARY}

A linear relationship was found between the radiance measured by the Landsat 2 MSS7 and the aerosol content above inland bodies of water. This relationship can be used to estimate the aerosol content with a standard deviation of $0.42 \mathrm{~N}$. This uncertainty is about three times greater than that found over the ocean for MSS6. Analysis of the data for MSS6 and MSS7 suggests that the larger uncertainty is mostly due to water turbidity, with little contribution from the adjacency effect.

It appears that the relationship found in this investigation would best be applied to determining an average aerosol content over a period of time at a given target, or an area average at a given time over several targets close together; the averaging could reduce the uncertainty in the measured aerosol content to a useful level.

It is recommended that the adjacency effect be investigated experimentally by conducting a study, similar to this investigation, using oligotrophic lakes as targets, thus el iminating water turbidity effects, with ground truth measurements of the optical thickness being made directly adjacent to the lakes. Such a program could provide input for modifying the theory of adjacency effects, and perhaps for determining an empirical correction, if necessary, for adjacency effects. 
Tropospheric aerosols play an important role in environmental quality on local, regional, and global scales. The local and regional aerosols impact mainly on the ambient air quality, and changes in the global background levels of aerosols may affect our climate. The use of space observations for monitoring tropospheric aerosols on a quantitative basis has been 1 imited to ocean areas. ${ }^{(1,2,3)}$ Landsat data ${ }^{(4)}$ were originally used to demonstrate that a 1 inear relationship exists between the upwelling visible radiance and the aerosol optical thickness (essentially all of this thickness is in the troposphere) over oceans. Since that time, similar relationships have also been found for sensors on the GOES and NOAA-5 satellites. (5) The 1 inear relationship has been shown theoretically to vary with the aerosol properties, such as size distribution and refractive index, al though the Landsat data obtained at San Diego showed little variability in the relationship. A global-scale ground-truth experiment was conducted by Science Applications, Inc. (SAI) and NOAA in the summer of 1980 with the AVHRR sensor on NOAA-6 to investigate the relationship at different sites around the globe.

It is desirable to extend the measurements over oceans to over 1 and masses. However, the 1 and measurements are much more difficult since the surface reflectance is high, so that the upwelling radiance comes mostly from the surface and is quite variable, both spatially and temporally. It was suggested in the SAI Landsat study (1) that the ocean technique might be use ful over land masses if the near infrared (MSS7) radiance over targets such as rivers, lakes, and reservoirs is used. This near infrared radiation does not penetrate water so deeply as the visible radiation, so that the upwelling near infrared radiance seen by the satellite is less influenced by the suspended matter generally found in the inland bodies of water. In addition to water turbidity effects, another potential problem for inland sites is the adjacency effect, in which the upwelling radiance above a small body of water is enhanced due to radiation reflected from the adjacent high albedo land.

The present investigation uses Landsat 2 radiance data and ground-truth measurements of the aerosol optical thickness, obtained previously at five inland sites, ${ }^{(1)}$ to study the usefulness and limitations of the near infrared radiance over inland bodies of water. 
2 .

The relationships $(1)$ between the upwelling visible radiance measured by Landsat 2 over oceans and the atmospheric aerosol content* are shown in Figure 2-1. The results for MSS7 are not shown since the low radiances for this channel were uncertain due to NASA procedures for producing the Landsat 2 computer compatible tapes. The correct radiance values for MSS7 must be obtained from the raw data tapes which are uncorrected for the different responses of the six detectors in each MSS channel. The problem did not exist with the Landsat 1 data tapes, and results for a11 four MSS channels were obtained, (1) as shown in Figure 2-2. (The differences between the relationships shown by Landsat 1 and Landsat 2 are attributed to differences in the radiometric calibrations of the sensors. (1),

It is seen in Figure 2-2 that the results for two inland bodies of water, a large lake at Grand Prairie, Texas, and a small reservoir at Atlantic City, New Jersey, show good agreement with the ocean data for MSS7. The Grand Prairie data are of particular interest since the MSS4, 5, and 6 black and white imagery clearly showed water pollution in the lake. The agreement with the ocean data is attributed to the fact that the MSS7 $(0.9 \mu \mathrm{m})$ radiation does not penetrate the water so deeply as the visible radiation, and hence is less influenced by the water pollution. It is also noted that the Atlantic City results do not show radiances higher than the ocean values, which would be expected due to the adjacency effect even if water pollution was not enhancing the radiance. These results and others led to the suggestion (1) that the MSS7 channel could be used to minimize water pollution effects on the radiance-aerosol content relationship, and that the adjacency effect is less than indicated by theoretical calculations.

In order to investigate the usefulness and limitations of using the upwelling near infrared radiance over inland bodies of water to determine the atmospheric aerosol content, ground-truth measurements, obtained previously(1),

\footnotetext{
*The aerosol content is defined in terms of the Elterman (6) model vertical aerosol optical thickness; i.e., the aerosol content is given by the ratio (measured aerosol optical thickness at wavelength $\lambda$ to the model aerosol optical thickness at wavelength $\lambda$ ) $\times \mathbb{N}$. In the results reported here, the wavelength is always $0.5 \mu \mathrm{m}$, and the model aerosol optical thickness is 0.213 (to the base e).
} 


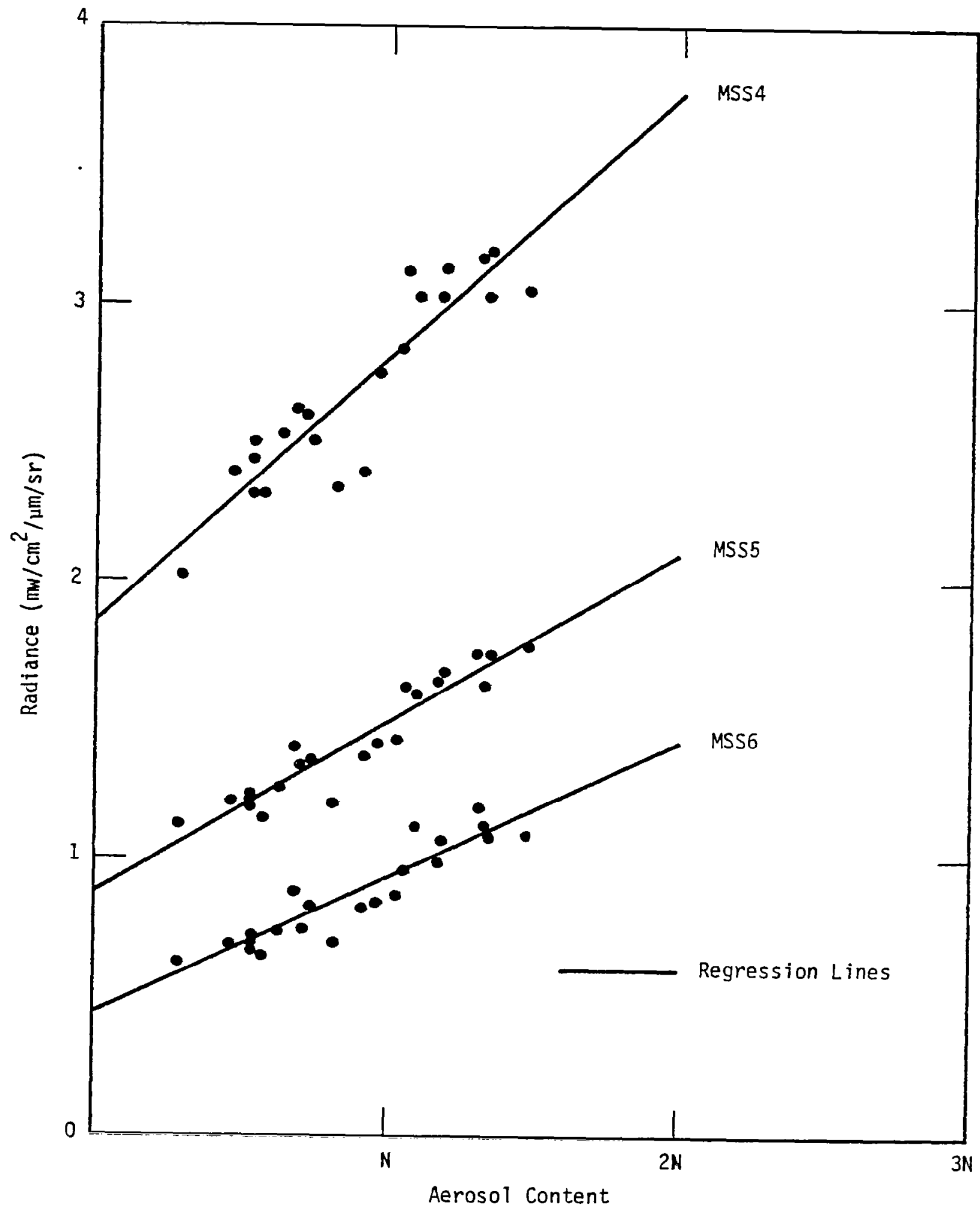

Figure 2-1. Landsat 2 Radiance vs Aerosol Content at San Diego for MSS4, MSS5, and MSS6. 


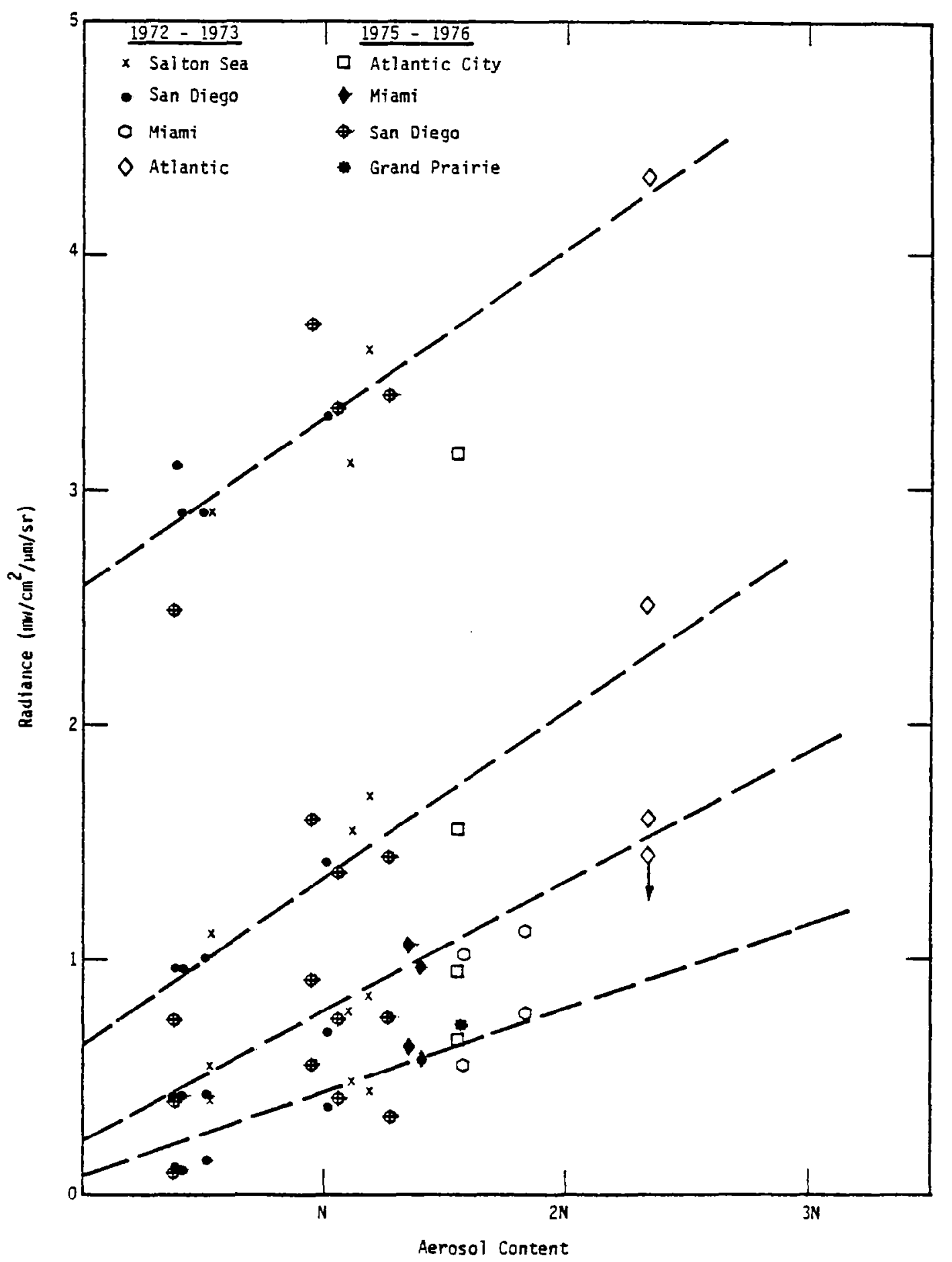

Figure 2-2. Landsat 1 Radiance vs Aerosol Content for Various Sites (from Reference 1). 
at five inland bodies of water for a total of twenty-four Landsat 2 overpasses have been used in conjunction with radiances determined from the raw data tapes for those overpasses. In addition, methods suggested by other workers for satellite measurements of aerosols over 1 and have been reviewed.

\section{$2.1 \quad$ Test Sites}

The ground-truth sites used in this investigation are listed in Table 2-1. The ground-truth measurements at San Diego were made by SAI personnel using a Volz sunphotometer. The Atlantic City site is part of the NOAA-EPA turbidity network which uses an Eppley sunphotometer. The LACIE (Large Area Crop Inventory Experiment) sites are operated by NASA-Johnson Space Center and utilize radiometers similar in principle to the Volz sunphotometer.

The inland site at Burke is a river about $500 \mathrm{~m}$ wide and $300 \mathrm{~m}$ from the sunphotometer location; the Divide target is a lake 2000 by $500 \mathrm{~m}$ at a distance of $500 \mathrm{~m}$ from the sunphotometer site; the Toole target is a 1 ake $500 \times 500 \mathrm{~m}$ at a distance of $3000 \mathrm{~m}$ from the sunphotometer site; the Hill target is a river about $1000 \mathrm{~m}$ wide and located about $8000 \mathrm{~m}$ from the sunphotometer site; and the Atlantic City target is a reservoir, approximately $300 \times 2000 \mathrm{~m}$, 1ocated about $2000 \mathrm{~m}$ from the sunphotometer site.

The ocean data, used as a reference set in analyzing the inland site data, were obtained at San Diego where the sunphotometer measurements were made on the shoreline, and the ocean target was about $1000 \mathrm{~m}$ from the sunphotometer site. 
Table 2-1. Test Sites

\section{SAI Site}

San Diego, California

NOAA - EPA Site

Atlantic City, New Jersey $32^{\circ} 45^{\prime} \mathrm{N}$

$117^{\circ} 10^{\prime} \mathrm{W}$

$39^{\circ} 27^{1} \mathrm{~N}$

$74^{\circ} 34^{\prime} W$

\section{LACIE Sites}

\begin{abstract}
Burke Co., N. Dakota
Divide Co., N. Dakota

Toole Co., Montana

Hill Co., Montana
\end{abstract}

$\begin{array}{lll}48^{\circ} & 53^{\prime} & \mathrm{N} \\ 48^{\circ} & 53^{\prime} & \mathrm{N} \\ 48^{\circ} & 53^{\prime} & \mathrm{N} \\ 48^{\circ} & 42^{\prime} & \mathrm{N}\end{array}$

$102^{\circ} 10^{\prime} \mathrm{W}$

$103^{\circ} 11^{\prime} \mathrm{W}$

$111^{\circ} 47^{\prime} \mathrm{W}$

$109^{\circ} 55^{\prime} \mathrm{W}$ 
A few techniques for satellite monitoring of tropospheric aerosols over 1 and have been suggested by other workers. Tropospheric measurements appear to be limited to the visible and near infrared spectral regions since the atmosphere is optically thick at shorter wavelengths and is too thin at longer wavelengths. Active (1aser) methods from satellites are not considered since they do not seem suited for tropospheric monitoring. (7) The method investigated in this report has limitations in that the ground resolution element of the satellite sensor must be smaller than the water target. In addition, the aerosol content is measured only above the water surface. However, the high resolution of the MSS, and the future thematic mapper, allows suitable bodies of water to be found in most areas. The other potential limitations of water pollution and the adjacency effect are discussed in later sections. The methods of other workers are outlined below.

Potter and Mendlowitz ${ }^{(8)}$ plotted the MSS4 radiance of each pixel in part of a Landsat scene against the MSS5 radiances of each pixel, and showed that the $y$-intercept of the regression 1 ine is correlated with the aerosol optical thickness. The results looked encouraging and were investigated further in this study, as discussed in Section 3.1 .

Potter and Mendlowitz ${ }^{(8)}$ al so showed that the minimum radiance values of MSS4 in a scene are related to the aerosol optical thickness, although the correlation does not look convincing. The method would probably look better if MSS7 radiances were used and if it were limited to scenes containing bodies of unpolluted water. Of course, the technique would then be essentially that which has been used over oceans, ${ }^{(1)}$ and is being investigated in this study for inland bodies of water.

Rogers ${ }^{(9)}$ plotted histograms of the pixel radiances for two Landsat-1 passes over Los Angeles, and showed that there was a general increase of the radiance values with an increase of haze. At low radiance levels this is basically the same as the minimum radiance method ${ }^{(8)}$; at high radiance 1 evels (corresponding to high reflectivities), the increase is surprising since both theory and desert data $(1)$ show the radiance at high reflectivities to remain essentially unchanged or to decrease. 
It has been suggested that information on aerosols could be obtained by angular scans of the sensor in azimuth or in nadir. This will certainly change the scattering angle of the observed radiation, and in theory, for a Lambertian surface reflectance and a horizontally homogeneous atmosphere, will permit determination of the aerosol content and other aerosol parameters. However, in practice these ideal conditions do not exist. In particular, the surface reflectance, which is generally non-uniform over land, can change quite rapidly due to rain or dust cover, and slowly due to man-made changes in structures and surfaces. In addition, the effective reflectance will vary with sun angle on a daily basis due to the presence of buildings, and on a seasonal basis due to the presence of vegetation. This method has recently been evaluated by Slater (10) for the purpose of making atmospheric corrections for future Landsat sensors.

Hariharan (11) has suggested that measurements of polarization of the upwelling visible radiation can determine the aerosol content. However this has the same limitations of the surface reflectance as the angular scan method, and in addition, has the problem of the unknown variability of the polarization properties of the surfaces.

A recent study by Barnes et al ${ }^{(12)}$ evaluated the capabilities of satellite observations to monitor regional air pollution episodes. In this technique the aerosol content is inferred by comparing the satellite radiance with the radiance calculated from a model. This method is discussed in detail in Section 3.2 .

3.1 Review of Potter and Mendlowitz ${ }^{(8)}$ Method

Potter and Mendlowitz (PM) divided an area (approximately $40 \times 20 \mathrm{~km}$ ) into 25 strips, each with 20 lines, and about 230 pixels wide. For each strip, the MSS4 digital count was plotted against that of MSS5 for each pixel to obtain a scatter diagram of about 4600 points. The $y$-intercepts of the regression lines for each of the 25 strips were averaged, and found to be correlated with the aerosol optical thickness. It would seem better to consider a smaller area centered on the ground-truth site since it is not certain that the atmosphere 
will be homogeneous over a $40 \times 20 \mathrm{~km}$ area. In this study, areas of $20 \times 10$ and $40 \times 20$ pixels centered on the ground-truth site were initially investigated. No significant difference in the regression lines was observed so the smaller area of $20 \times 10$ pixels $(1.4 \times 0.7 \mathrm{~km})$ was used for economy in computing time. In addition to comparing MSS4 and 5, MSS5 and 6, and MSS4 and 7 were compared; before plotting and computing the regression lines, each count value is divided by the cosine of the sun zenith angle to provide an approximate normalization for intercomparison of different scenes, as done by PM.

The results for the three scenes analyzed are given in Table 3-1; these particular scenes were chosen to cover a wide range of aerosol content $(N)$.

Table 3-1. Regression Line Intercept (a) and Slope (b)

\begin{tabular}{lccccccccc} 
& & \multicolumn{9}{c}{ MSS 4} & vs 5 & MSS 5 vs 6 & \multicolumn{2}{c}{ MSS 4 vs 7} \\
Place & Date & $\underline{N}$ & $\underline{a}$ & $\underline{b}$ & $\underline{a}$ & $\underline{b}$ & $\underline{a}$ & $\underline{b}$ \\
Atlantic City & $7-18-76$ & 1.76 & -1.44 & 1.03 & 0.00 & 0.52 & -0.14 & 0.70 \\
Altantic City & $4-18-76$ & 3.29 & -0.32 & 0.90 & -0.05 & 0.87 & -0.33 & 1.28 \\
Toole & $7-10-76$ & 0.44 & -0.20 & 0.84 & -0.60 & 0.82 & -1.24 & 1.07
\end{tabular}

The scatter diagrams showing the regression lines for two of the scenes are shown in Figures 3-1 to 3-6 (Band 1 is MSS4, Band 2 is MSS5, Band 3 is MSS6, and Band 4 is MSS7). In these diagrams, the number of pixels having the same values are represented by the number up to 9 pixels, and then by $A, B, C, \ldots$ for $10,11,12, \ldots$ pixels. The best correlation is found for MSS4 vs MSS5, with the other channel correlations being particularly poor for Toole. However, the $y$-intercept values for MSS4 vS MSS5 show no correlation with the aerosol content, and show little difference in value, whereas PM showed a change from 14 to 22 counts for the same angle of $N$. A limited hand check using a smaller area made in 1977 by SAI using San Diego Landsat data had also found intercepts near zero, and uncorrelated with $N$. Thus, it appears that the results of Potter and Mendlowitz cannot be duplicated. 


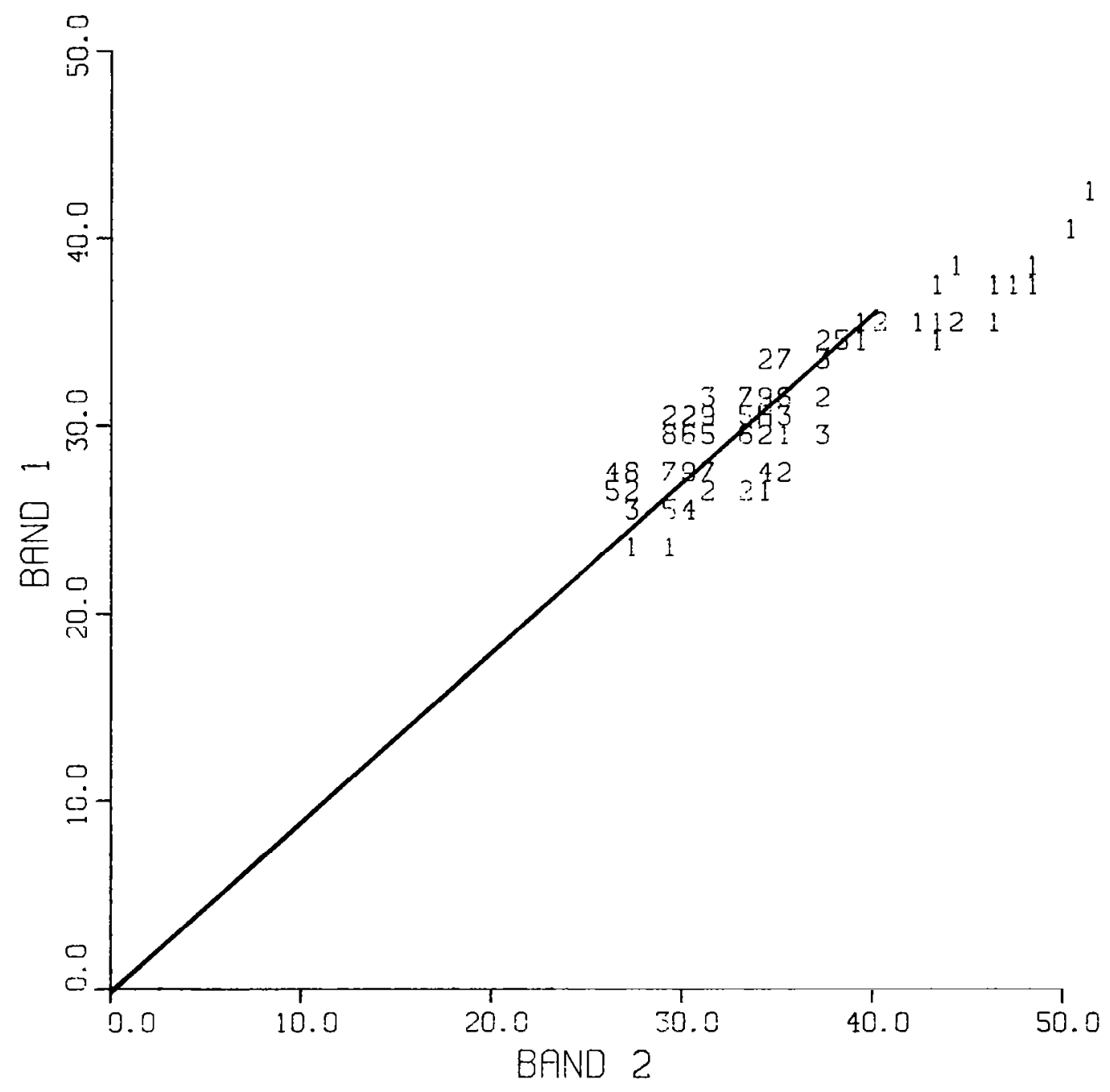

Figure 3-1. MSS4 (Band 1) Radiance vs MSS5 (Band 2) Radiance At Tantic City 4-18-76. 


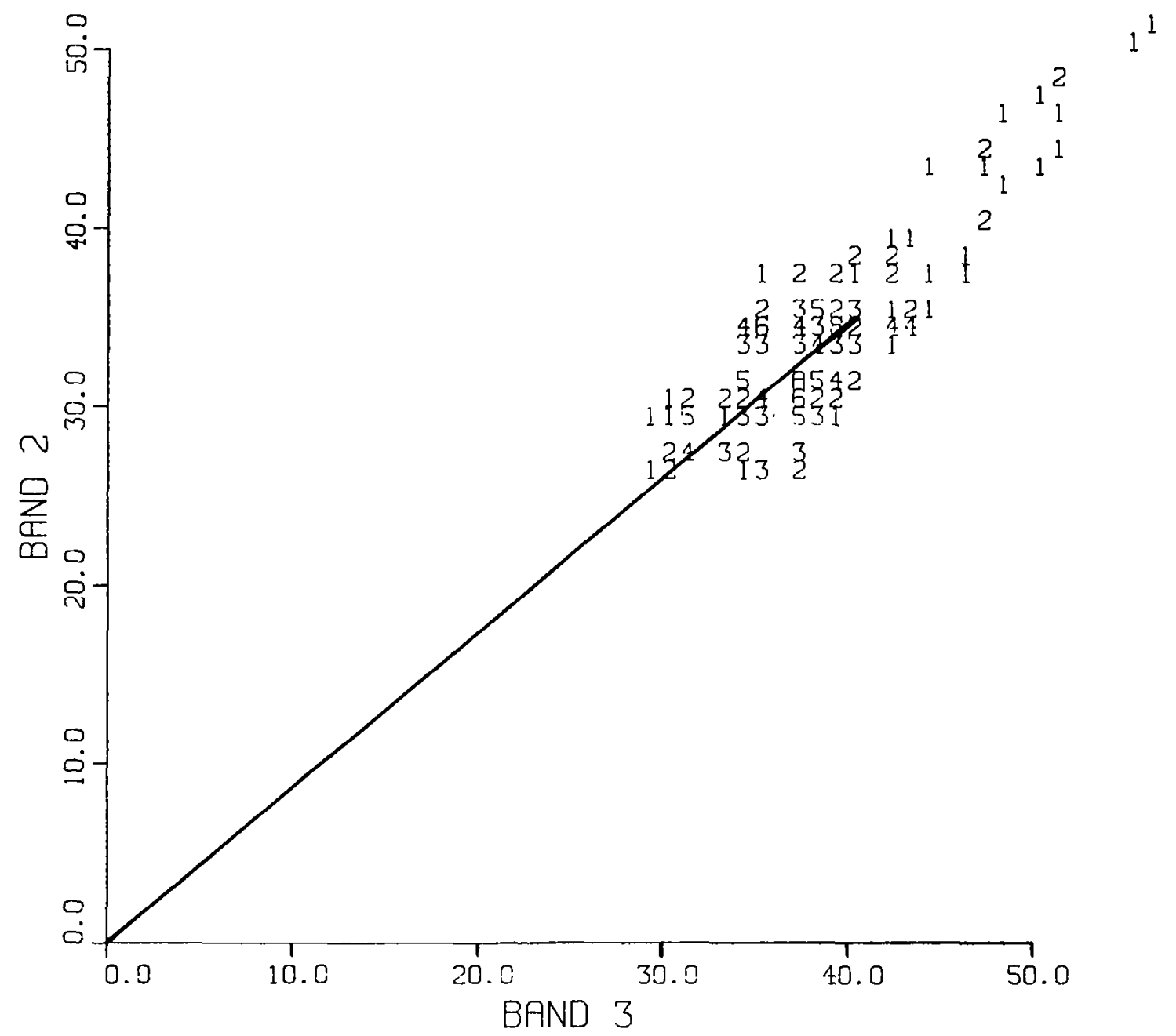

Figure 3-2. MSS5 (Band 2) Radiance vs MSS6 (Band 3) Radiance Atlantic City 4-18-76. 


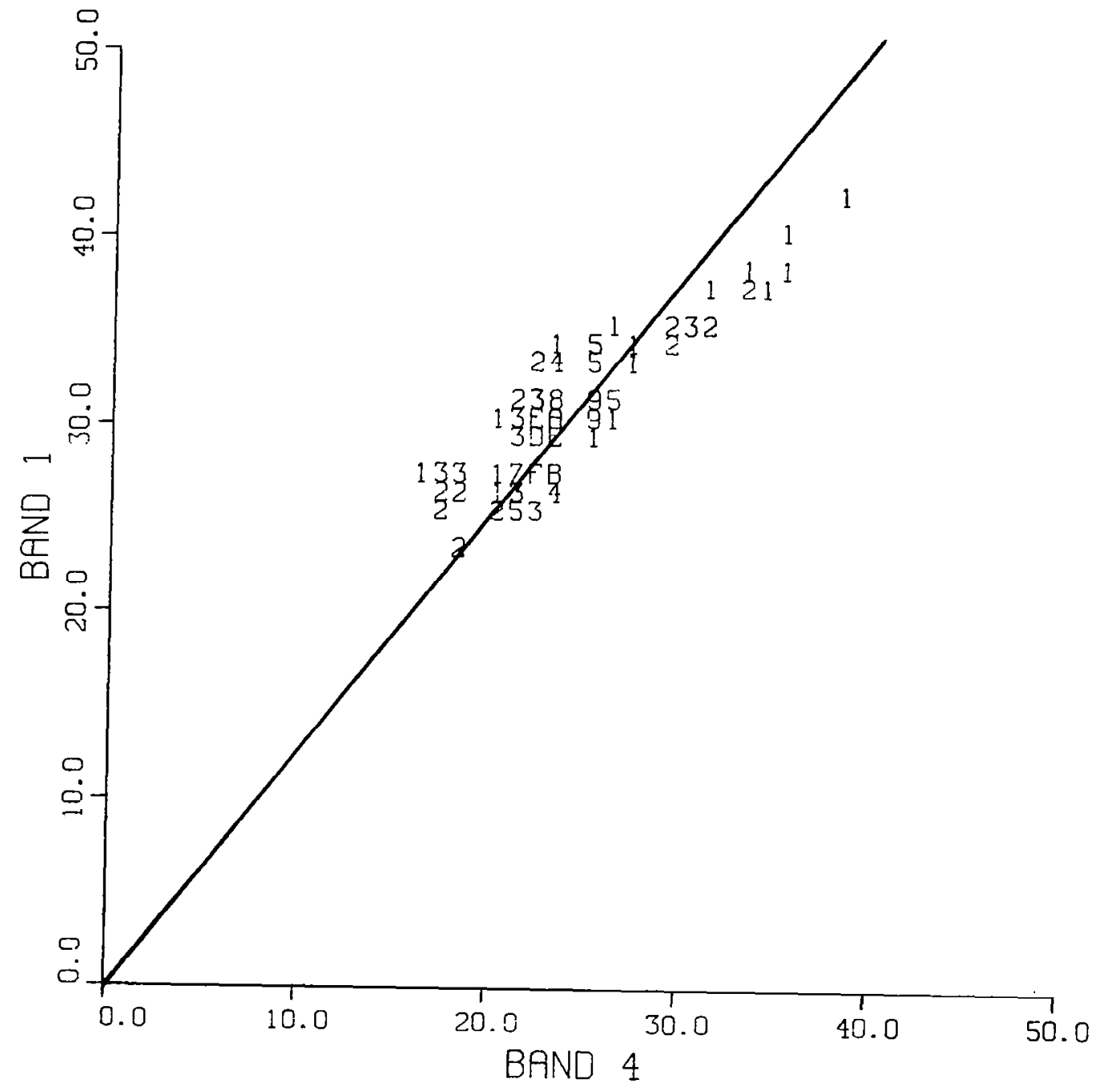

Figure 3-3. MSS4 (Band 1) Radiance vs MSS7 (Band 4) Radiance Atlantic City 4-18-76. 


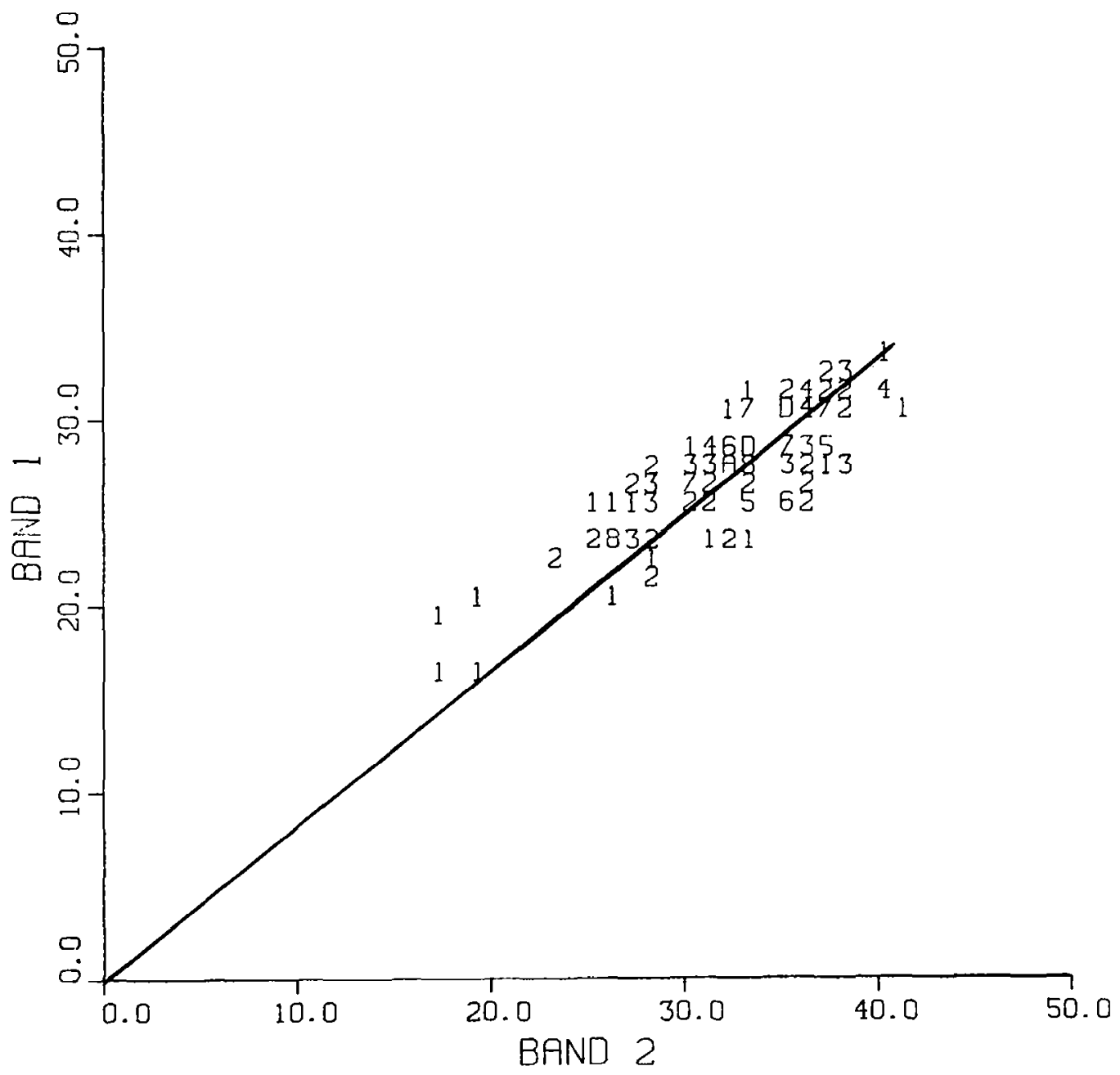

Figure 3-4. MSS4 (Band 1) Radiance vs MSS5 (Band 2) Radiance Toole 7-10-76. 


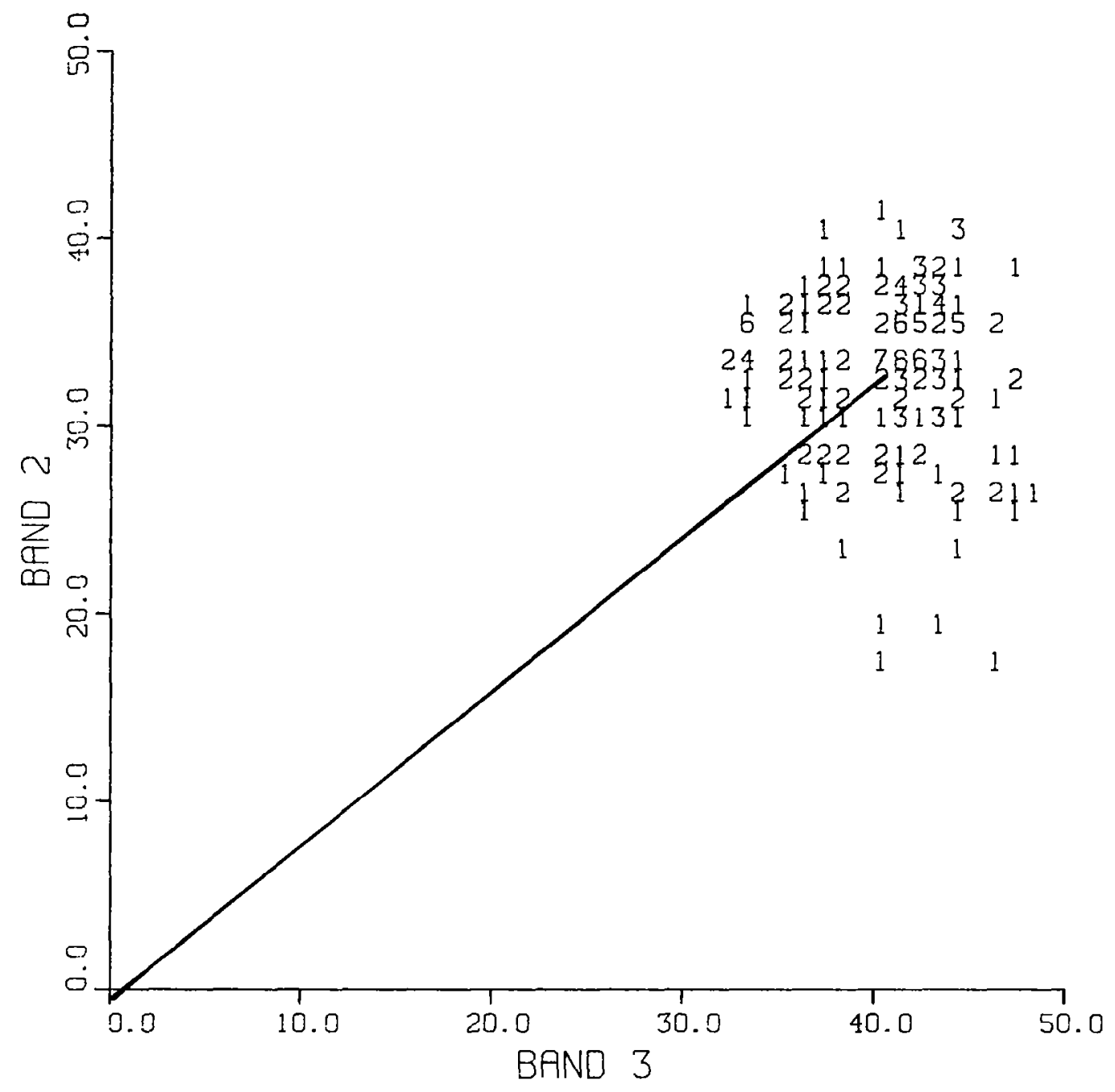

Figure 3-5. MSS5 (Band 2) Radiance vs MSS6 (Band 3) Radiance Toole 7-10-76. 


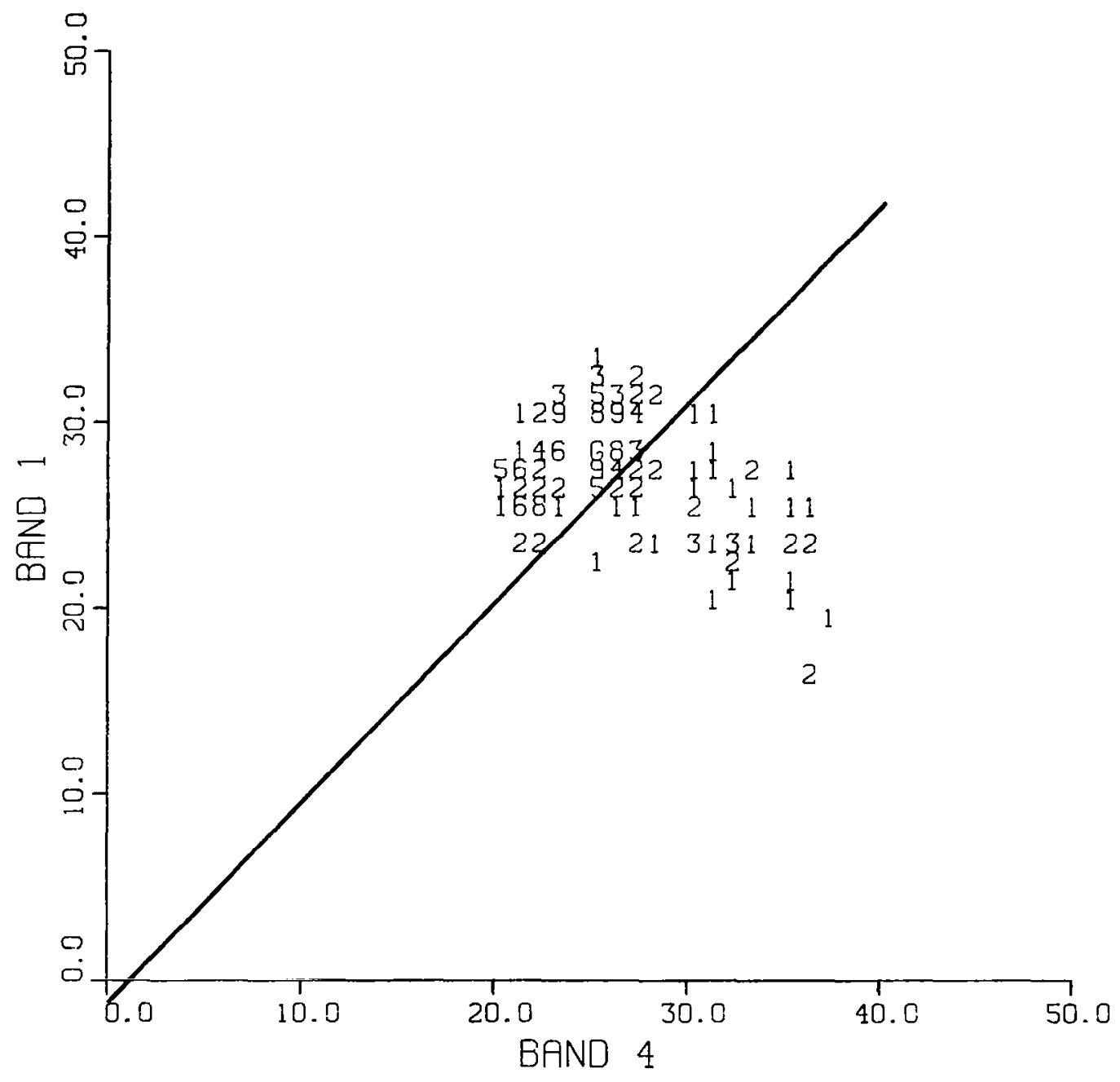

Figure 3-6. MSS4 (Band 1) Radiance vs MSS7 (Band 4) Radiance Toole 7-10-76. 
3.2 Review of Barnes et al (12) Method

The work of Barnes et al evaluated the use of satellite observations to monitor regional air pollution episodes, and attempted to relate the digitized visible radiance data to the measured sulphate aerosol values using a radiative transfer model. By making various assumptions regarding the aerosol composition, surface reflectivity and the mixing height of the pollution layer, good agreement was found between the satellite and surface measurements of the sulphate aerosol concentration. However, it should be noted that the agreement is strongly dependent on the model parameters, particularly the surface reflectivity, which is generally not known precisely.

Calculations by Griggs $(1)$ show that the upwelling visible radiance is most sensitive to the aerosol loading at low surface reflectivities. As shown in Figure 3-7, at low reflectivities the radiance increases with the aerosol loading, but at high albedos the radiance actually decreases as the aerosol amount increases. High albedos are generally found only over deserts, snow or clouds, so that for most of the earth's surface, increasing aerosol amounts result in increasing radiance. However, it is clear from Figure 3-7 that the radiance changes due to aerosol changes are best observed over oceans $(A=0)$, with the sensitivity decreasing over 1 and surfaces $(A=0.1-0.2$ typically). In addition, it can be seen that an error in estimating the surface reflectivity of the 1 and can strongly affect the estimate of the aerosol amount from a radiance measurement. For example, a radiance of about $3 \mathrm{mw} / \mathrm{cm}^{2} / \mathrm{um} / \mathrm{sr}$ could be interpreted as zero aerosol content for $A=0.15$ or as $3 \mathrm{~N}$ for $\mathrm{A}=0.10$.

The calculations by Barnes et al, using their variational-iterative technique, and those by Griggs, using the Dave code, cannot be compared exactly from their published results since Barnes et al give radiance ratios rather than actually radiances, and different wavelengths, sun angles and aerosol models are used. However, the two sets of calculations may be compared approximately. The aerosol content ( $N$ ) of Griggs represents the vertical optical thickness of the aerosols at $0.5 \mu \mathrm{m}(1 \mathrm{~N}=.213$ optical thickness $)$. Since about $90 \%$ of the vertical optical thickness is typically in the lowest $3 \mathrm{~km}$ of the atmosphere, it 


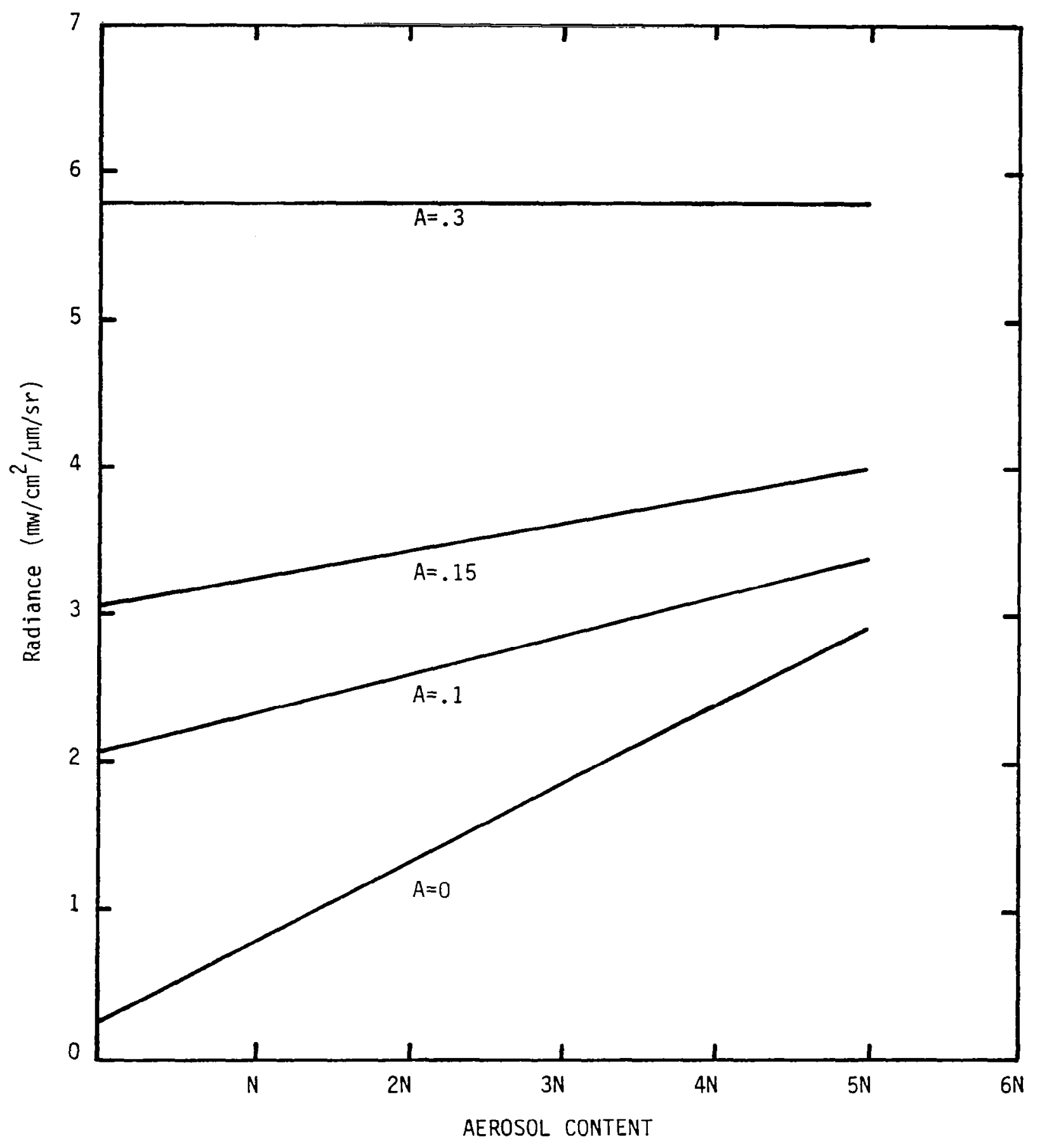

Figure 3-7. Calculated Radiance vs. Aerosol Content as Function of Albedo for $0.75 \mu \mathrm{m}$. (Sun Zenith Angle $=63^{\circ}$; Refractive Index $=1.5$; Junge Size Distribution Parameter $=4.0$ ). 
can be assumed that $N$ is directly related to the optical extinction in the surface layer. In the El terman ${ }^{(6)}$ model used by Griggs, $1 \mathrm{~N}$ corresponds to a surface visibility of $25 \mathrm{~km}$ at $0.5 \mu \mathrm{m}$. The Barnes et al model assumes that a surface visibility of $23 \mathrm{~km}$ at $0.55 \mu \mathrm{m}$ (approximately the same as the Griggs model) corresponds to a sulphate concentration of $10 \mu \mathrm{g} / \mathrm{m}^{3}$. Since Barnes et al assume that the sulphate concentration is directly proportional to the optical thickness, then it follows that $1 \mathrm{~N}$ is approximately equivalent to $10 \mu \mathrm{g} / \mathrm{m}^{3}$ of sulphate aerosols, i.e.,

$$
\text { Aerosol Content }=0.1\left[\mathrm{SO}_{4}^{--}\right] \mathrm{N}
$$

The Barnes et al model also includes other particulate matter in addition to the sulphates, but maintains a constant ratio between the two types so that Equation 3-1 is still correct.

The model conditions for the Barnes et al calculations (sun zenith angle $=60^{\circ}$, view angle $=0^{\circ}, \lambda=0.65 \mu \mathrm{m}$ ) are similar to those used by Griggs ( sun zenith angle $=63^{\circ}$, view angle $=0^{\circ}, \lambda=0.75 \mu \mathrm{m}$ ) in Figure 3-7. Thus the results in Figure 3-7 are plotted as radiance ratios and compared directly with the Barnes et al results in Figure 3-8. The agreement for $A=0.1$ is good and essentially verifies that both calculations are probably yielding similar results. Figure 3-8 also shows the results of Griggs for $A=0.15$ and clearly indicates that a small change in surface reflectivity produces a large change in the estimated sulphate concentration.

In addition to the problem of varying surface reflectivity, it should be noted that a measurement of intensity ratios suggested by Barnes et al is subject to significant errors. A ratio measurement of $\pm 10 \%$ is probably optimistic, and as seen in Figure 3-9, it would result in a 1 arge uncertainty in the sulphate concentration.

As discussed earlier, observations of aerosols over a 1 and surface are difficult due to the fact that the surface reflectivity is generally not known and is quite variable both spatially and temporally. These errors due to surface reflectivity could be minimized by estimating the value of the surface 


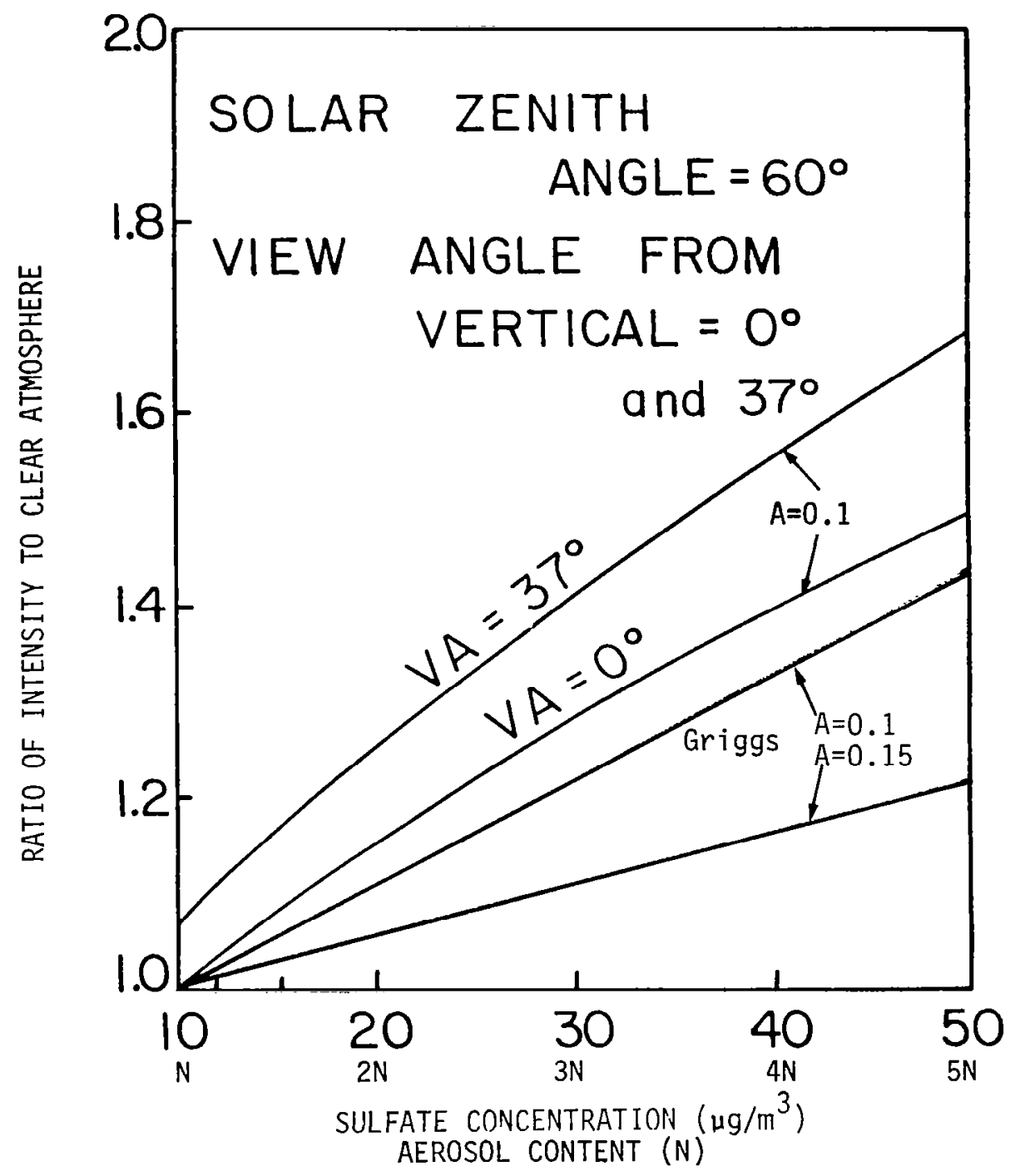

Figure 3-8. Comparison of Barnes et al and Griggs Calculations . 


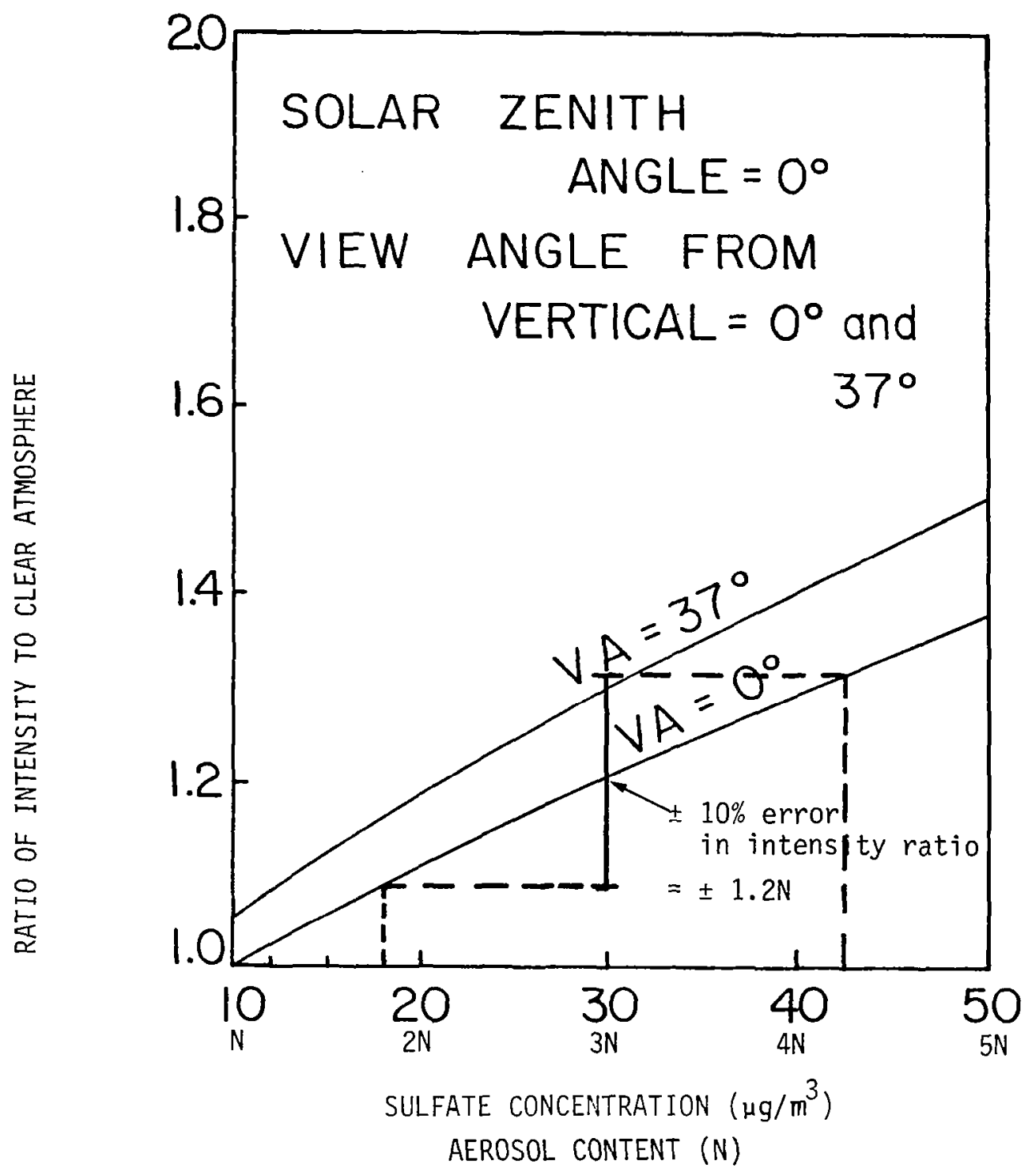

Figure 3-9. Effect of Measurement Errors ( $\pm 10 \%)$ on Determination of Aerosol Content. 
reflectivity from clear day observations, and by averaging over several resolution elements. The former task is probably not simple, due to the reflectivity changing with sun angle and weather conditions on a diurnal basis, and with vegetation changes on an annual basis. If these errors can be reduced to acceptable values, then the accuracy of the radiance values measured by the satellite may become more important.

It was suggested by Barnes et al that the GOES system would be useful for quantitatively monitoring regional air pollution episodes. However, the GOES data are digitized in large radiance steps so that each step covers a large range of optical thickness. The sensitivities of different satellite systems are. illustrated in Figure 3-10. These plots are determined from the digital count vs. radiance for each satellite, in conjunction with the radiance vs. aerosol content for $A=0.1$ in Figure 3-7. It is clear that the GOES system is the least desirable from the standpoint of sensitivity to aerosol changes. The most sensitive satellite system is the AVHRR on the NOAA-6, which gives a sensitivity three times better than the MSS on Landsat, four times better than the VHRR on NOAA-5, and five times better than the VISSR on GOES. * These sensitivities shown in Figure 3-10 will be degraded by noise in the sate 11 ite system, but NOAA-6 will clearly provide the best sensitivity to aerosol changes.

* Noted added in press: Private communications from J. Barnes of ERT and R. Fraser of NASA-GSFC indicate that anaiyses of NOAA-5 and GOES data for elevated pollution episodes in the northeastern United States have shown greater radiance sensitivity to aerosol content than suggested by the calculations in Figure 3-10. 


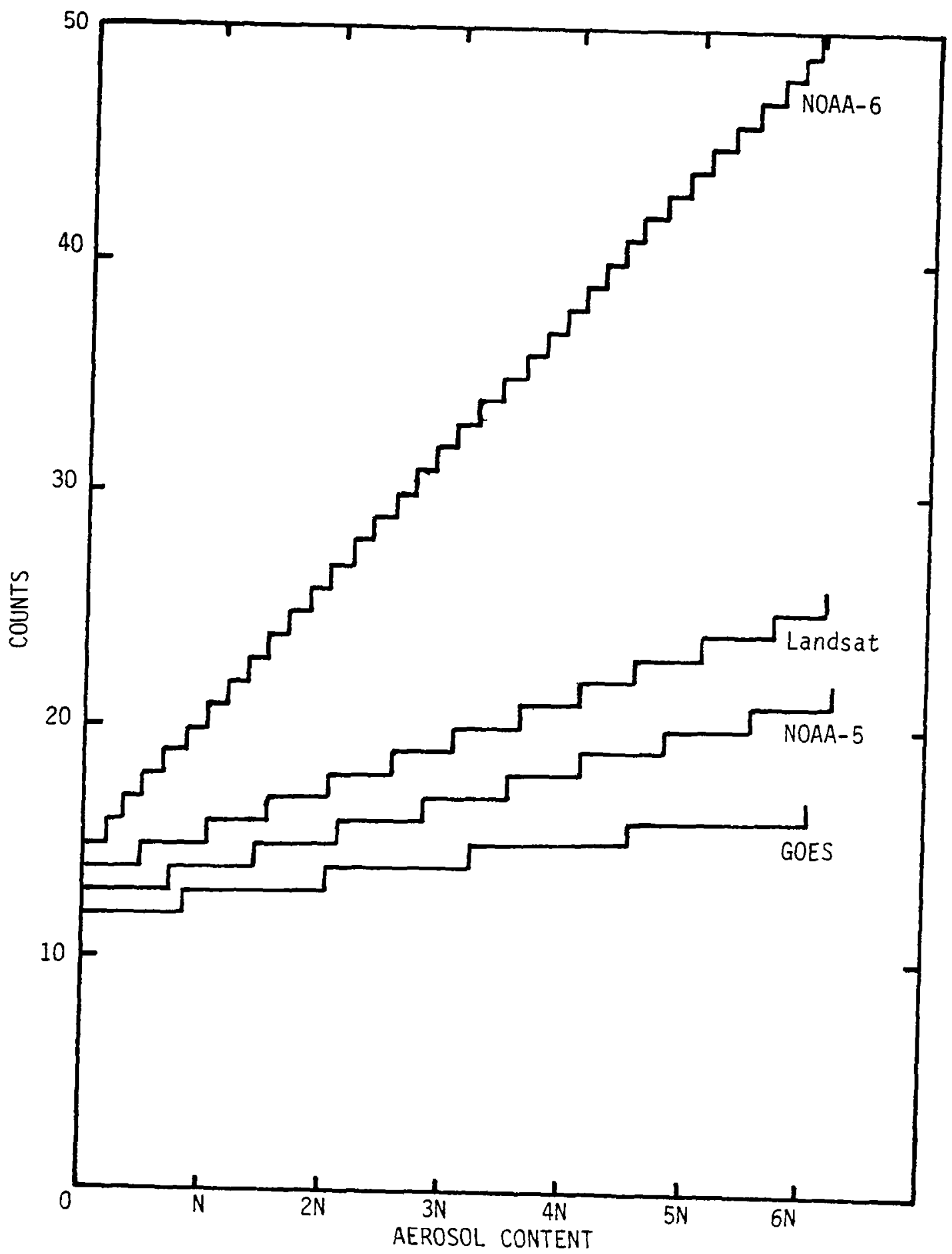

Figure 3-10. Digital Counts ys Aerosol Content over Land $(A=0.1)$ for
Different Satellite Systems. 
The method of analyzing the Landsat computer compatible tapes and raw tapes has been described previous1y. (1) In this study an improved sun-angle correction factor has been applied to the measured MSS radiances to normalize them to standard conditions.

\subsection{Radiance Data}

\subsubsection{Sun Correction Factor}

In order to compare Landsat data taken at different times, and hence different sun angles, the radiance values are normalized to standard conditions of nadir viewing $(\theta=0)$ and a sun zenith angle $\left(\theta_{0}\right)$ of $63.3^{\circ}$. The correction factors applied to the measured radiance values are determined from theoretical calculations. In the previous Landsat study(1) a single set of correction factors, based on Monte Carlo calculations, was applied to each MSS channel. For this study, improved sun-angle correction factors have been calculated separately for each channel, using the Dave ${ }^{(13)}$ code and a model which fit the Landsat 2 data obtained at San Diego ${ }^{(1)}$. The sun correction factors for MSS6 and iMSS7 which are used in this study are shown in Figures 4-1 and 4-2.

\subsubsection{Water Vapor Correction for MSS7}

There is significant absorption by atmospheric water vapor in the spectral bandpass of MSS7. Pitts et al ${ }^{(14)}$ calculated the atmospheric transmission for the MSS7 channel as a function of water vapor content. Their results, based on high spectral resolution calculations, are shown in Figure 4-3. For convenience in this study, the curve in Figure 4-3 has been approximated by the equation

$$
\tau=\exp \left(-.094 u^{.43}\right)
$$

where $\tau$ is the path transmission and

$$
u=w\left(1+\sec \theta_{0}\right)
$$




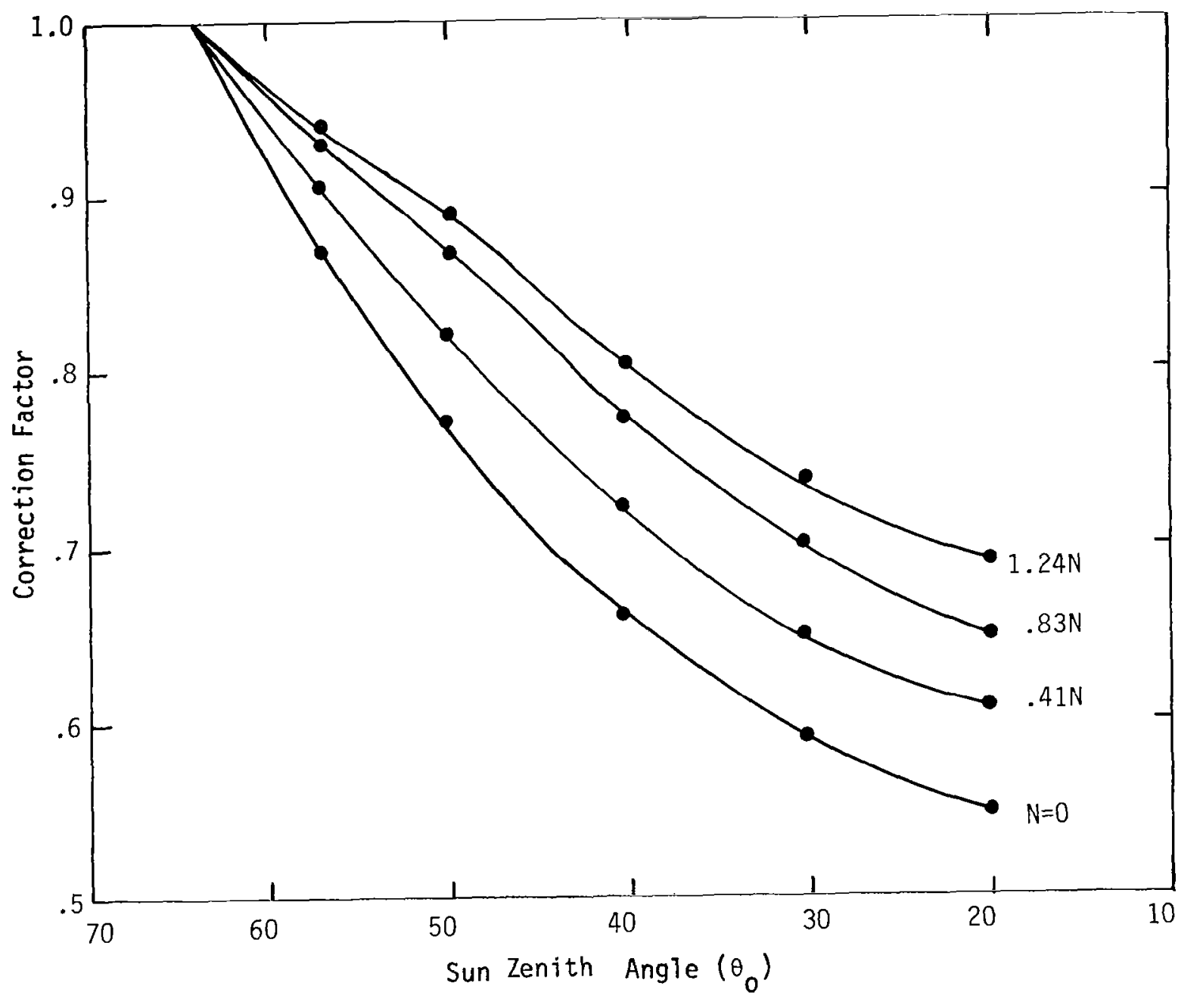

Figure 4-1. Sun-Angle Correction Factor for MSS6. 


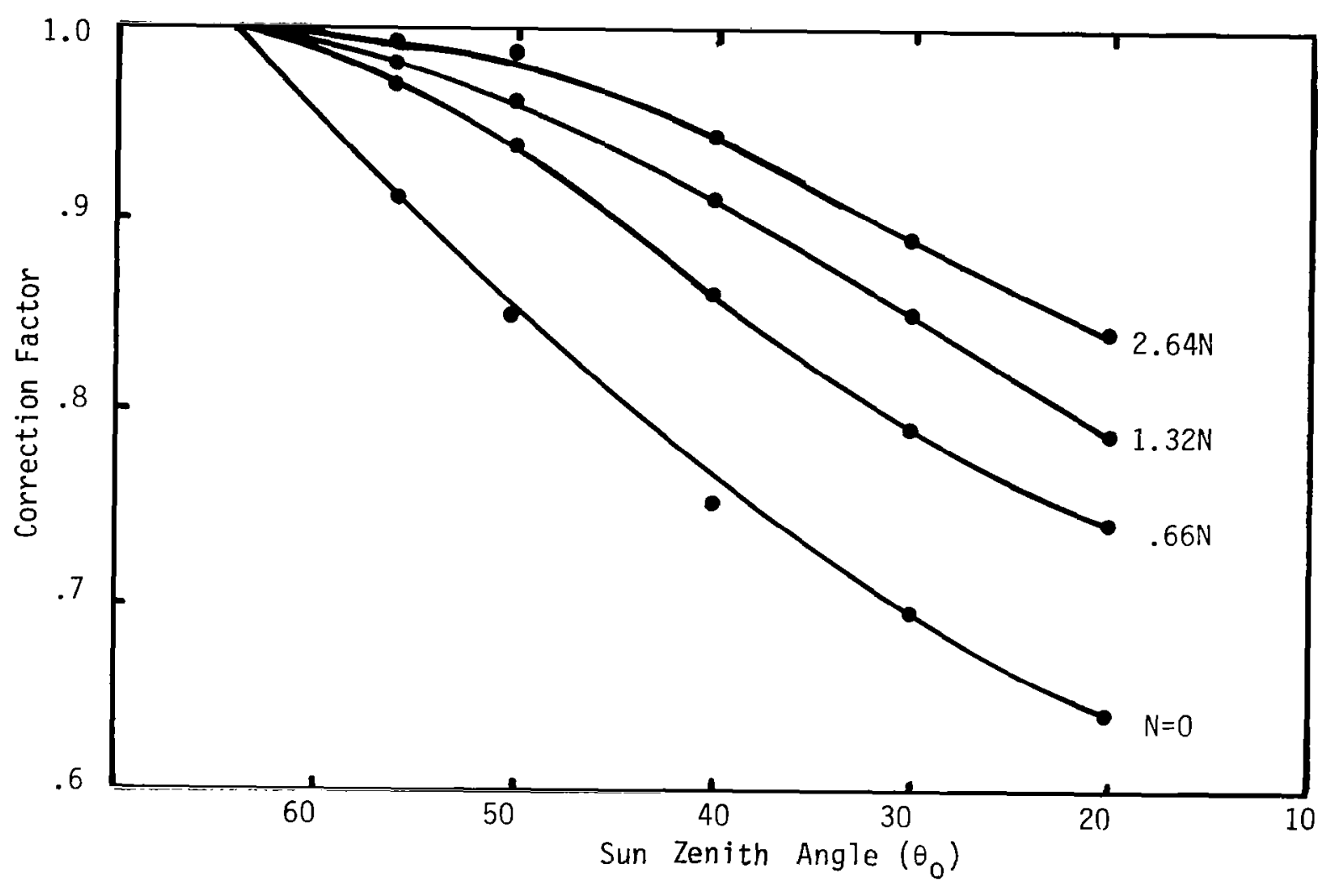

Figure 4-2. Sun-Angle Correction Factor for MSS7.

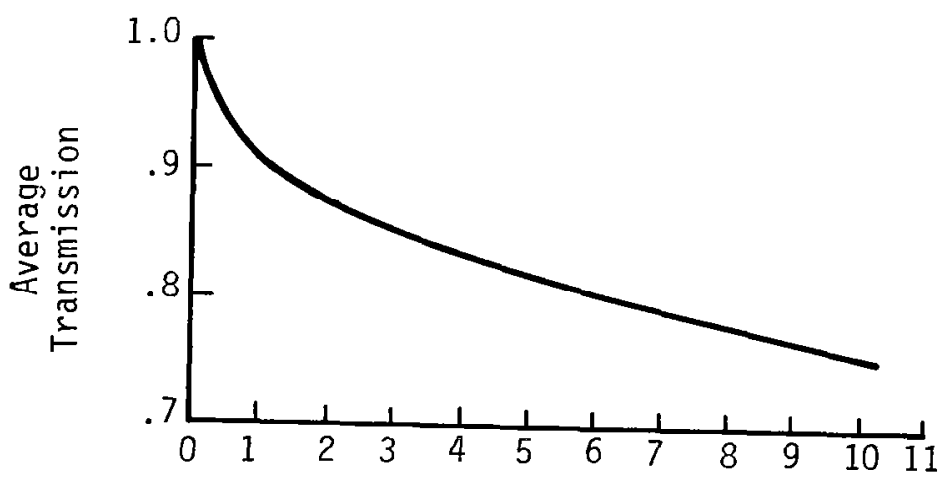

Total Atmospheric Water Content (Precipitable $\mathrm{cm}$ )

Figure 4-3. Calculated Transmission of Water Vapor in the MSS7 Band. 
where $w$ is the vertical water vapor content in preciptable $\mathrm{cm}$ and $\theta_{0}$ is the sun zenith angle.

The values of $w$ were determined for each Landsat overpass analyzed in this study by obtaining preciptable water vapor maps of the United States, or selected radiosonde data if the maps were not available, from the National Climatic Center in Ashville.

The water vapor correction is applied to the MSS7 radiance values by multiplying them by $1 / \tau$. This approach, used by Pitts et al is a simplified one, ignoring scattering effects, but is justified since the correction is small, and, as is shown in Section 5 , is not of significance in this study.

\subsection{Sunphotometer Data}

The method of analyzing sunphotometer data is well established and has often been described (e.g., Flowers et al ${ }^{(15)}$ ). In this study, special consideration was given to the reliability of the instruments, since significant calibration problems have been experienced with the NOAA-EPA turbidity network sunphotometer (E. Flowers, NOAA, private communication). 
Significant results were obtained in this investigation; a linear relationship was found between the MSS7 radiance and aerosol content at the inl and sites, but with higher radiance values and more scatter of data points than found over the ocean. By comparing the data at the inland sites with the ocean data of San Diego, it is inferred that most of the differences are due to water turbidity effects.

\subsection{Radiance Data}

The radiance values, for the inland sites, determined from the raw data tapes are compared in Table 5-1 with those obtained previously(1) from the calibrated tapes, using the same pixels in each case. It is noted that, as expected, the main differences between the tapes occur in the lowest radiance values. Also shown in Table 5-1 are the normalized radiance values, obtained previously(1) with the calibrated data, and those determined by applying the new sun-angle correction factor (Figure 4-2) to the raw radiance values. It is seen that the normalized raw radiances are significantly different from the normalized radiances that were obtained previously from the calibrated tapes.

\subsubsection{Water Vapor Correction}

Water vapor data were obtained from the National Climatic Center in Ashville in the form of precipitable water vapor maps of the United States, and radiosonde data for Glasgow AB, Montana, and Great Falls, Montana, for five dates for which maps were not available. These data are available only for times different from the Landsat overpasses, being about two hours earlier at Atlantic City, and about four hours earlier at the other sites, so some small differences probably exist between these measured water vapor amounts and those observed by Landsat. Fortunately, as seen in Figure 4-3, the water vapor transmission factor to be applied to the MSS7 radiance data is not very sensitive to changes in the water vapor content. 
Table 5-1. Comparison of Raw and Calibrated Radiances (MSS7)

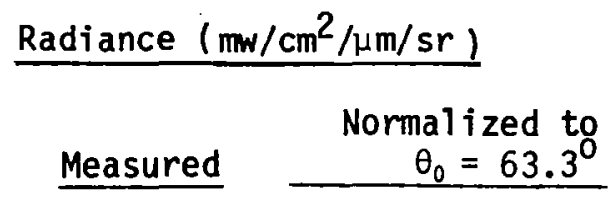

\begin{tabular}{|c|c|c|c|c|c|}
\hline Target & Date & Calibrated & $\underline{\text { Raw }}$ & Calibrated & Raw \\
\hline $\begin{array}{c}\text { Atlantic City } \\
\text { (Reservoir) }\end{array}$ & $\begin{array}{l}4-18-76 \\
6-12-76 \\
7-18-76 \\
8-22-76 \\
4-19-76 \\
8-23-76 \\
9-28-76\end{array}$ & $\begin{array}{l}1.35 \\
1.35 \\
0.87 \\
1.62 \\
1.77 \\
1.58 \\
0.76\end{array}$ & $\begin{array}{l}1.46 \\
1.30 \\
0.85 \\
1.65 \\
1.75 \\
1.57 \\
0.65\end{array}$ & $\begin{array}{l}1.17 \\
1.00 \\
0.66 \\
1.36 \\
1.47 \\
1.40 \\
0.68\end{array}$ & $\begin{array}{l}1.39 \\
1.16 \\
0.76 \\
1.57 \\
1.67 \\
1.50 \\
0.62\end{array}$ \\
\hline Toole (Lake) & $\begin{array}{l}6-04-76 \\
7-10-76 \\
7-28-76 \\
9-20-76 \\
7-22-77 \\
4-23-77 \\
5-11-77\end{array}$ & $\begin{array}{l}0.95 \\
0.78 \\
0.61 \\
0.61 \\
0.61 \\
0.61 \\
0.61\end{array}$ & $\begin{array}{l}0.95 \\
0.56 \\
0.59 \\
0.24 \\
0.53 \\
0.76 \\
0.60\end{array}$ & $\begin{array}{l}0.71 \\
0.59 \\
0.47 \\
0.57 \\
0.48 \\
0.51 \\
0.48\end{array}$ & $\begin{array}{l}0.79 \\
0.44 \\
0.48 \\
0.22 \\
0.42 \\
0.63 \\
0.47\end{array}$ \\
\hline Burke(River) & $\begin{array}{r}5-28-76 \\
7-21-76 \\
10-01-76 \\
6-28-77\end{array}$ & $\begin{array}{l}0.81 \\
1.32 \\
0.61 \\
0.84\end{array}$ & $\begin{array}{l}0.79 \\
1.27 \\
0.62 \\
0.86\end{array}$ & $\begin{array}{l}0.59 \\
0.99 \\
0.60 \\
0.63\end{array}$ & $\begin{array}{l}0.64 \\
1.12 \\
0.61 \\
0.68\end{array}$ \\
\hline Divide(Lake) & $\begin{array}{l}8-09-76 \\
9-14-76\end{array}$ & $\begin{array}{l}0.61 \\
0.61\end{array}$ & $\begin{array}{l}0.62 \\
0.66\end{array}$ & $\begin{array}{l}0.51 \\
0.56\end{array}$ & $\begin{array}{l}0.52 \\
0.60\end{array}$ \\
\hline Hill (River) & $\begin{array}{r}5-16-76 \\
9-19-76 \\
10-07-76 \\
8-08-77\end{array}$ & $\begin{array}{l}0.68 \\
0.61 \\
0.61 \\
0.61\end{array}$ & $\begin{array}{l}0.80 \\
0.32 \\
0.39 \\
0.67\end{array}$ & $\begin{array}{l}0.51 \\
0.57 \\
0.59 \\
0.50\end{array}$ & $\begin{array}{l}0.68 \\
0.31 \\
0.38 \\
0.60\end{array}$ \\
\hline
\end{tabular}


The vertical water vapor contents determined from the maps or radiosonde data are shown for the sites in Table 5-2, together with the transmission factors computed from Equation 4-1. The mean value of the transmission for this data set is $0.85 \pm 0.06$ which is close to the value of $0.81 \pm 0.10$, suggested in our Landsat 2 study, ${ }^{(1)}$ to be used in the absence of water vapor information.

The normalized radiance values before and after correction for the water vapor absorption are also given in Table 5-2. It should be noted that these radiance values have been normalized to the mean earth-sun distance since the data were obtained at different times of the year. These radiance values before and after the water vapor correction are plotted against the aerosol content $(N)$ in Figures $5-1$ and $5-2$, respectively. It is seen that the scatter of points is about the same in each figure, suggesting that the water vapor amount has little influence on the use of the MSS7 radiance to infer the aerosol content. This is perhaps more clearly shown by considering the regression line and error of estimate before and after the water vapor correction. The 1 inear regression line for the uncorrected radiances $R$ is

$$
R=.39+.38 \mathrm{~N}
$$

with a correlation coefficient $(r)$ of 0.91 , and a standard error of estimate $\left(s_{d}\right)$ of 0.17

For the corrected radiances, the regression 1 ine is

$$
\begin{aligned}
& R=.44+.46 \mathrm{~N} \\
& r=.91 \\
& s_{d}=.22
\end{aligned}
$$

It is seen that the correction changes the regression line as expected, but that the correlation coefficient is unchanged, and that the error of estimate is actually larger with the correction. 
Table 5-2. Radiance Values (MSS7) Corrected for Water Vapor Absorption

\begin{tabular}{|c|c|c|c|c|c|c|}
\hline Target & Date & $\begin{array}{c}\text { Vertical } \\
\text { Water Vapor } \\
\text { Content (pr.cm) } \\
\end{array}$ & Transmission $(\tau)$ & $\begin{array}{c}\text { Normalized } \\
\text { Radiance } \\
\left(\mathrm{mw} / \mathrm{cm}^{2} / \mu \mathrm{m} / \mathrm{sr}\right)\end{array}$ & $\begin{array}{c}\text { Corrected } \\
\text { Radiance } \\
\left(\mathrm{mw} / \mathrm{cm}^{2} / \mu \mathrm{m} / \mathrm{sr}\right) \\
\end{array}$ & $\begin{array}{c}\text { Aerosol } \\
\text { Content }(N) \\
\end{array}$ \\
\hline $\begin{array}{c}\text { Atlantic City } \\
\text { (Reservoir) }\end{array}$ & $\begin{array}{l}4-18-76 \\
6-12-76 \\
7-18-76 \\
8-22-76 \\
4-19-76 \\
8-23-76 \\
9-28-76\end{array}$ & $\begin{array}{l}1.93 \\
2.54 \\
1.22 \\
3.81 \\
1.52 \\
2.54 \\
2.54\end{array}$ & $\begin{array}{l}0.85 \\
0.82 \\
0.87 \\
0.79 \\
0.85 \\
0.82 \\
0.81\end{array}$ & $\begin{array}{l}1.40 \\
1.20 \\
0.79 \\
1.62 \\
1.69 \\
1.53 \\
0.62\end{array}$ & $\begin{array}{l}1.65 \\
1.46 \\
0.90 \\
2.06 \\
1.99 \\
1.87 \\
0.77\end{array}$ & $\begin{array}{l}3.29 \\
2.18 \\
1.76 \\
2.99 \\
2.89 \\
2.94 \\
0.72\end{array}$ \\
\hline Toole (Lake) & $\begin{array}{l}6-04-76 \\
7-10-76 \\
7-28-76 \\
9-20-76 \\
7-22-77 \\
4-23-77 \\
5-11-77\end{array}$ & $\begin{array}{l}1.40 \\
1.80 \\
0.66 \\
0.79 \\
1.83 \\
0.76 \\
1.20\end{array}$ & $\begin{array}{l}0.86 \\
0.84 \\
0.89 \\
0.89 \\
0.84 \\
0.89 \\
0.87\end{array}$ & $\begin{array}{l}0.81 \\
0.45 \\
0.50 \\
0.22 \\
0.43 \\
0.64 \\
0.48\end{array}$ & $\begin{array}{l}0.95 \\
0.54 \\
0.56 \\
0.25 \\
0.52 \\
0.72 \\
0.55\end{array}$ & $\begin{array}{l}0.72 \\
0.44 \\
0.44 \\
0.30 \\
0.20 \\
0.11 \\
0.06\end{array}$ \\
\hline Burke (River) & $\begin{array}{r}5-28-76 \\
7-21-76 \\
10-01-76 \\
6-28-77\end{array}$ & $\begin{array}{l}1.02 \\
2.27 \\
1.42 \\
1.27\end{array}$ & $\begin{array}{l}0.88 \\
0.83 \\
0.84 \\
0.86\end{array}$ & $\begin{array}{l}0.66 \\
1.16 \\
0.61 \\
0.70\end{array}$ & $\begin{array}{l}0.75 \\
1.40 \\
0.73 \\
0.82\end{array}$ & $\begin{array}{l}0.58 \\
0.95 \\
0.72 \\
0.39\end{array}$ \\
\hline Divide (Lake) & $\begin{array}{l}8-09-76 \\
9-14-76\end{array}$ & $\begin{array}{l}2.29 \\
1.16\end{array}$ & $\begin{array}{l}0.82 \\
0.86\end{array}$ & $\begin{array}{l}0.54 \\
0.61\end{array}$ & $\begin{array}{l}0.65 \\
0.71\end{array}$ & $\begin{array}{l}0.30 \\
0.30\end{array}$ \\
\hline Hill (River) & $\begin{array}{r}5-16-76 \\
9-19-76 \\
10-07-76 \\
8-08-77\end{array}$ & $\begin{array}{l}0.50 \\
0.88 \\
0.76 \\
1.25\end{array}$ & $\begin{array}{l}0.91 \\
0.87 \\
0.88 \\
0.86\end{array}$ & $\begin{array}{l}0.70 \\
0.31 \\
0.38 \\
0.62\end{array}$ & $\begin{array}{l}0.77 \\
0.36 \\
0.43 \\
0.72\end{array}$ & $\begin{array}{l}0.67 \\
0.62 \\
0.53 \\
0.77\end{array}$ \\
\hline
\end{tabular}




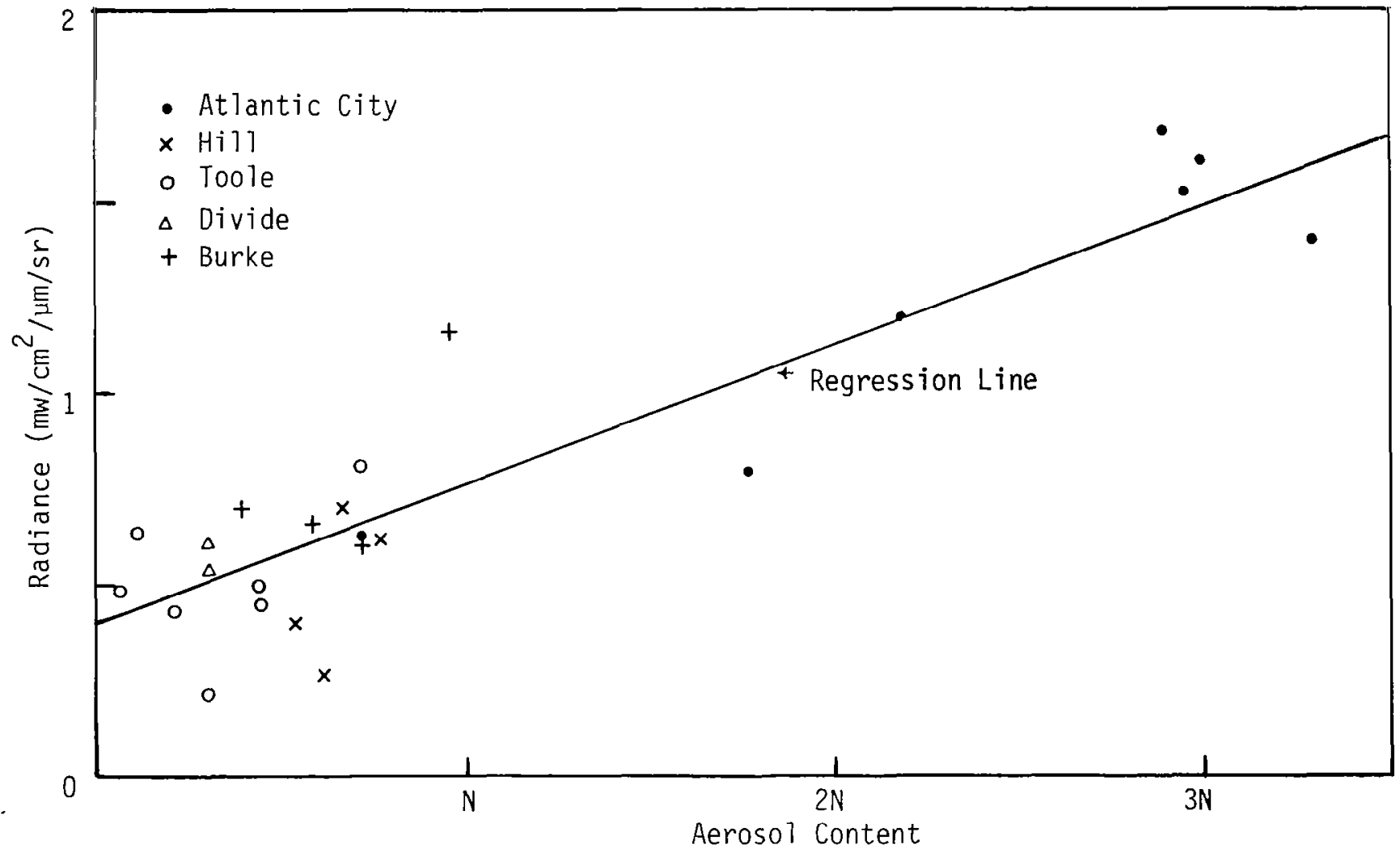

Figure 5-1. Radiance vs Aerosol Content for MSS7 (uncorrected for water vapor). 


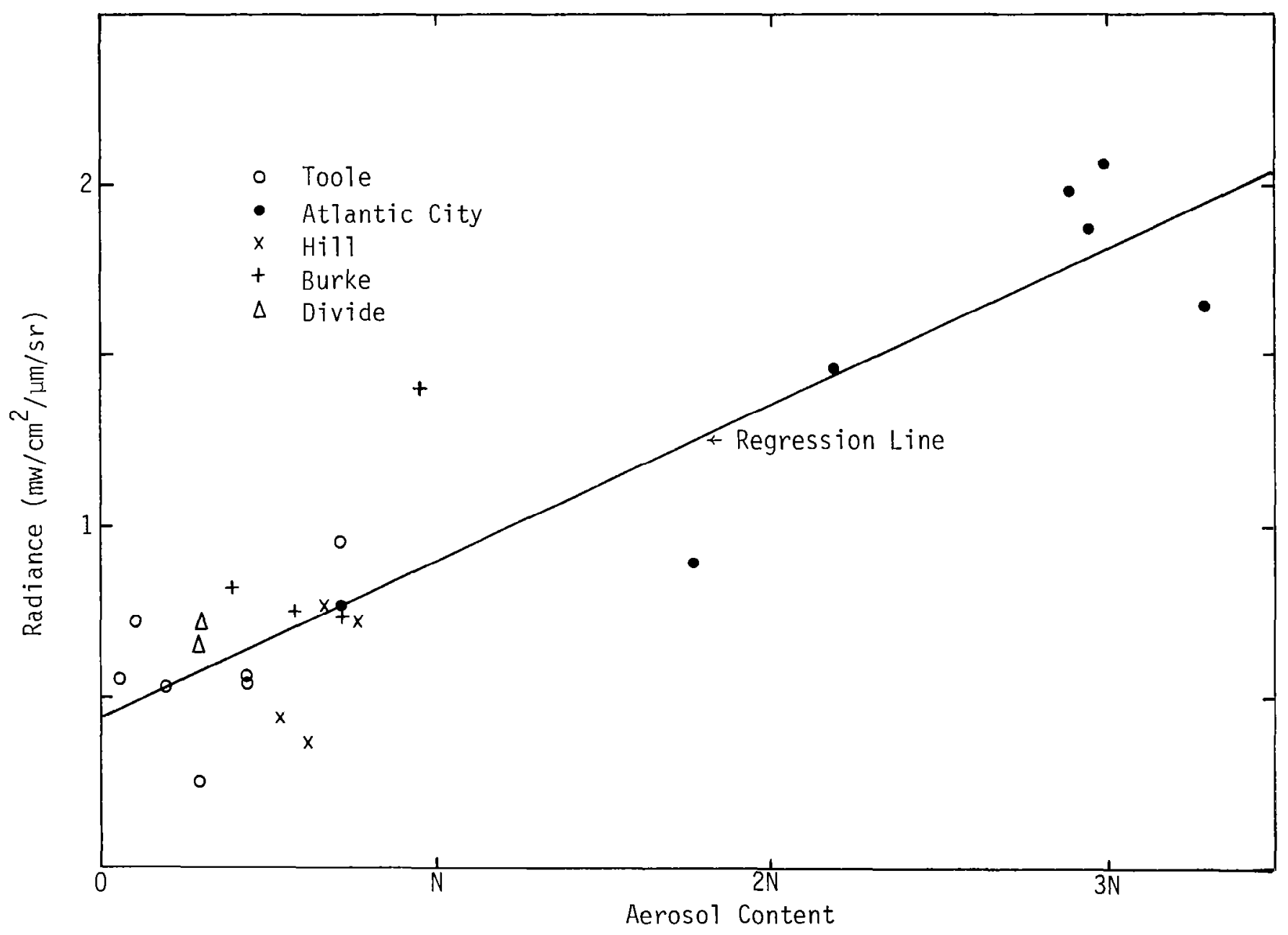

Figure 5-2. Radiance vs Aerosol Content (MSS7) (corrected for water vapor). 
It is apparent in comparing the MSS7 radiance-aerosol content relationship for the inland sites (Figure 5-1) with the MSS6 relationship obtained for San Diego (Figure 2-1) that the inland sites not only show considerably more scatter of data points, but al so show higher radiance values than expected.

The larger scatter of points for MSS7 may be due to (1) errors in the sunphotometer data, (2) radiance errors in the MSS7 data tapes, (3) errors in the sun correction factors, (4) water vapor absorption effects in MSS7, (5) more variability in the aerosol properties at the inland sites, (6) variability in the adjacency effect at the inland sites, and (7) variability in the inland water turbidity. The higher than expected radiance values for MSS7 may be due to (1) the adjacency effect, (2) water turbidity effects, (3) the aerosol properties being different between the inland and ocean sites, and (4) incorrect radiance calibrations being used for MSS7. These error sources are discussed in the following section.

\subsection{Error Sources}

\subsubsection{Sunphotometer Errors}

The San Diego data were always taken with the same Volz sunphotometer whose calibration was checked periodically and found to be stable, so the error should not be more than about \pm 0.02 in optical thickness, or $\pm 0.1 \mathrm{~N}$. The data for the present inland sites were obtained by different instruments at each site, so there is more potential for error. However, the instruments used at the LACIE sites were carefully checked before and after the program by NASA-JSFC, and it is considered that the instruments were stable. The accuracy in the actual readings made in the field is perhaps questionable since professional observers were not used. A larger error is possible for the Atlantic City site which is part of the turbidity network operated by NOAA-EPA. Considerable calibration problems have been experienced with their sunphotometers ( $E$. Flowers, NOAA, private communication). In a study (16) with NOAA, we have found up to $16 \%$ changes in the $I_{0}$ of the NOAA-EPA sunphotometers in a period of a year. This is equivalent to 
an error of .160 in optical thickness, or $0.75 \mathrm{~N}$, for unit airmass (the error would be $50 \%$ of this for a measurement through an airmass of two). No information is available on the stability of the instrument at Atlantic City, except for a three-point Langley plot made with data obtained on 4-18-76 lone of the overpasses used in this study). Although only three points are not generally considered useful, on this occasion the plot did show excellent agreement with the given instrument calibration. In addition, the scatter of the Atlantic City data about the regression line seems similar to that of the LACIE data, so it is assumed that no unusual instrument errors are associated with it.

In summary, the aerosol content is probably accurate to about $\pm 0.1 \mathrm{~N}$, and the instrument errors do not significantly contribute to the scatter of data points.

\subsubsection{Radiance Errors}

Fraser made calculations of the noise equivalent radiance (NER) of a single pixel for each of the Landsat 1 MSS channels based on prefiight calibrations obtained through the complete system, including the digitization.

The NERs, as shown by Griggs, (1) are equivalent to approximately half a digital count in each channel, so that we can say that the radiance error for a single pixel is \pm 1 count with a probability of 0.95 . There appear to be no similar calculations for Landsat 2 readily available, but it is reasonable to assume that the errors are very similar. The errors are, of course, reduced by the square root of the number of pixels when averaging over a target area.

For the San Diego and Salton Sea targets of our previous study, the digital counts were averaged over 40 pixels, whereas the inland targets, being smal1, permitted averaging only over 9 pixels, so the errors in the San Diego and Salton Sea data should be about half those for the inland data, in a given MSS channe1. The radiance errors for the different target sizes, assuming an NER of half a count for a single pixel, are given in Table 5-3. These errors should be reduced by the sun correction factor ( 0.85 average) when applying them to the radiance-aerosol content relationship. It is noted that MSS7 shows a 1 arger error than MSS6 so that a larger scatter of points would be expected in MSS7 than in MSS6, as found in Section 5.2. 
Table 5-3. MSS Radiance Errors (NER) $\left(\mathrm{mw} / \mathrm{cm}^{2} / \mu \mathrm{m} / \mathrm{sr}\right)$ for Different Target Sizes 1 Pixel 9 Pixels (inland) 40 Pixels (ocean)

MSS4

.100

.033

.016

MSS5

.067

.022

.011

MSS6

.058

.019

.009

MSS7

.168

.056

.027

Based on the good linear radiance-aerosol content relationship found at San Diego, it is assumed that the MSS calibrations were quite stable during the period 1975-1977, when the data for this study were gathered. However, the absolute accuracy of the MSS radiance values is uncertain; our previous study (1) showed that calibration differences existed between Landsat 1 and Landsat 2.

\subsubsection{Sun-Angle Correction Factor Errors}

The sun correction factors are different for each MSS channel due to the difference in wavelength, and are based on calculations with the Dave scattering code. Since the same range of sun angle is found for each data set (ocean and inland) the correction factors probably do not contribute to any differences between the data sets.

\subsubsection{Water Vapor Absorption Effects}

It was shown in Section 5.1.1 that the correction for water vapor absorption in the MSS7 radiances did not significantly change the scatter of data points in the radiance-aerosol content relationship. Thus, it is assumed that the uncorrected radiance values at San Diego and the inland sites may be directly compared wi thout significant uncertainty. 


\subsubsection{Effects of Aerosol Properties}

The previous study ${ }^{(1)}$ showed theoretically that a change in the aerosol properties (size distribution and refractive index) causes a change in the slope of the radiance-aerosol content relationship. Thus, a different slope of the radiance-aerosol content relationship might be observed at inland sites, where continental aerosols predominate, in comparison with the ocean site, where maritime aerosols predominate. In addition, the properties of the aerosols are likely to be more variable at the inland sites than over the ocean, thus producing more scatter in the inland data points.

\subsubsection{Adjacency Effects}

The higher albedo 1 and surrounding an inland body of water is theoretically predicted to increase the radiance values over the water. In addition, the difference in the size of each body of water, the difference in the type of surrounding terrain, and the changes in the terrain albedo between overpasses at each site, should all contribute to scatter in the data points in the radiance-aerosol content relationship. A detailed discussion of adjacency effects is given in Section 5.4.

\subsubsection{Water Turbidity Effects}

Suspended matter in water increases the apparent reflectivity of the water since some of the solar radiation which penetrates the water is backscattered by the particles, thus increasing the upwelling radiance observed by the satellite. For the MSS6 channel, the radiation penetrates about $40 \mathrm{~cm}$, and for MSS7, about $14 \mathrm{~cm}$. Thus, the MSS7 radiance is less susceptible to suspended matter, but it can be seen clearly in MSS4, 5, and 6 imagery, that considerable water turbidity (man-made or natural) occurs in many inland bodies of water. Even if the water turbidity is not apparent in the MSS7 imagery, it may sti11. affect the more sensitive digital radiance data. Thus, the MSS7 radiances for inland bodies of water might be higher than for the ocean which generally shows little suspended matter except in some coastal regions. In addition, the variability of the water turbidity should contribute to the scatter of points in the inland radiance-aerosol content plots. 
Both water turbidity and the surrounding higher albedo 1 and are expected to produce similar effects on the radiance observed over the body of water. However, the relative importance of each effect can perhaps be deternined since the adjacency effect theoretically depends on various measurable parameters such as size of the body of water, land albedo, and aerosol content, all of which should not influence the water turbidity effect. This possibility is discussed in Section 5.5 .

\subsection{Adjacency Effects}

It has been theoretically predicted $(17,18,19)$ that the presence of high albedo 1 and adjacent to the low albedo water target can significantly increase the radiance observed over the water in comparison with an infinite body of water. This potential problem was recognized in our original Landsat 1 study, (20) and San Diego and Salton Sea data indicated that the effect was negligible beyond about $400 \mathrm{~m}$ from the boundary between 1 and and water. The present study enables a more detailed investigation of the effect, which depends on the size of the water body, on the magnitude of the 1 and albedo, and on the aerosol content, to be made since these parameters all vary at the inland sites.

\subsubsection{Theory}

The Monte Carlo calculations of Pearce (18) appear better suited to the present analysis than the work of Turner ${ }^{(17)}$ or Otterman and Fraser (19), since the latter two studies use only a simplified single scattering atmospheric model. In addition, the results of Pearce are presented in a form which can readily be compared to the Landsat data being analyzed in this present study.

Pearce made calculations of the variation of intensity across the boundary between two semi-infinite surfaces of differing Lambertian albedo as a function of aerosol optical thickness and wavelength for several pairs of albedos. The pairs did not include albedos of 0 and 0.2 which would best represent the water and 1 and surfaces in the present study, but the results given by Pearce can be interpolated/extrapolated since he shows that the adjacency effect is proportional to the albedo difference between the two surfaces. The results for an albedo pair $(0,0.2)$ in Figure 5-3 were determined from plots given 


\section{WAVELENGTH $=0.55 \mu \mathrm{m}$}

RECEIVER ALTITUDE $=704 \mathrm{~km}$

RECEIVER FOOTPRINT $=.03 \mathrm{~km}$ square

SOLAR ZENITH ANGLE $=40^{\circ}$

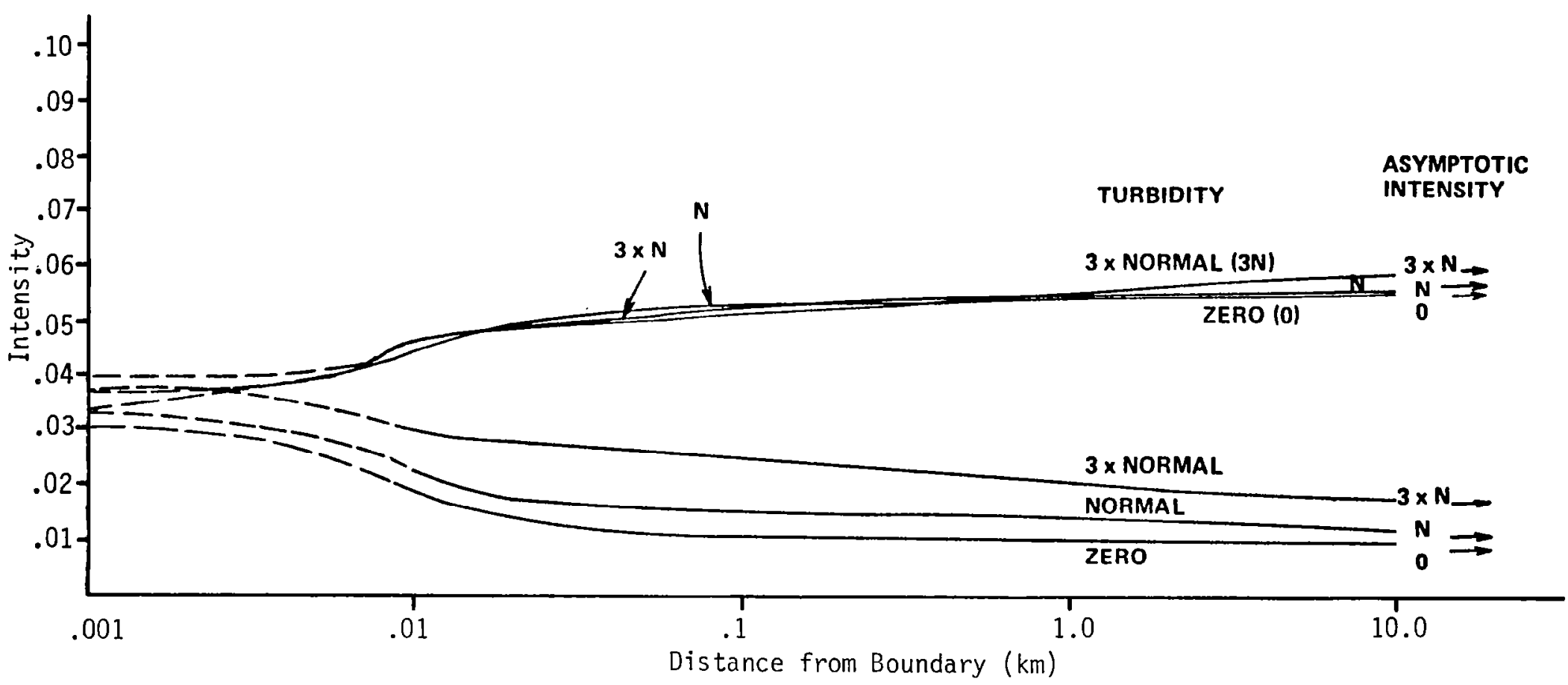

Figure 5-3. Intensity vs Distance from Boundary for Step Function Albedo Pattern $(0,0.2)$ (after Pearce(18)). 
by Pearce, and show that the radiance value levels off rapidly when passing from a land surface to the ocean, especially for zero to normal aerosol content. However, it is noted that even at $10 \mathrm{~km}$ distance, the asymptotic radiance value has not been reached; at the 1 to $2 \mathrm{~km}$ distance used for the San Diego site, the plots indicate a radiance about $15 \%$ higher than an infinite surface of zero albedo. Pearce also shows that the adjacency effect is approximately independent of wavelength, being about the same for a given aerosol optical thickness regardless of wavelength, thus enabling Figure 5-3 to be applied to all MSS channels. ( $N$ represents an optical thickness of 0.212 in the work of Pearce.)

Pearce also made calculations for a square target surrounded by an infinite surface of a different albedo, which can be related to the inland bodies of water in this study. Figure 5-4, which is deduced from the plots given by Pearce, shows the radiance at the center of the target for two albedo pairs, $(0,0.2)$ and $(0.2,0)$, as a function of the size of the target. The smallest dimension of each target in this study are marked on the abscissa. Examination of Figure 5-4 in comparison with Figure 5-3 shows that for inland sites the radiances, for the albedo pair $(0.0 .2)$ should be higher than at the ocean by about $5 \%$ for $0 \mathrm{~N}, 20 \%$ for $1 \mathrm{~N}$, and $45 \%$ for $3 \mathrm{~N}$. (These values are just rough estimates as they are based only on the plots shown by Pearce, since he does not provide numerical data; and, our targets are not square, and are not surrounded by a uniform surface.) These predicted differences must be modified in comparing our ocean and inland targets, since the 1 and albedo at San Diego for MSS7 is about 0.35 compared to about 0.20 at the inland sites. The figures of Pearce are not precise, and do not allow the albedo effect to be estimated, but as noted earlier, the adjacency effect is proportional to the albedo difference. If this proportionality applies to distances of 1 to $2 \mathrm{~km}$ from the boundary, it is found that the radiance at the inland sites would actually be about $5 \%$ lower than at the ocean at San Diego for $\mathrm{ON}$, and only 15\% higher for $N$ and $35 \%$ higher for $3 N$.

\subsubsection{Landsat Data}

The theoretical results may be compared with the Landsat data obtained at San Diego and the Salton Sea in our previous study. A review of the San Diego data showed that the ocean radiances become essentially constant within 2 pixels of the coasti ine independent of wavelength and aerosol content for the range 


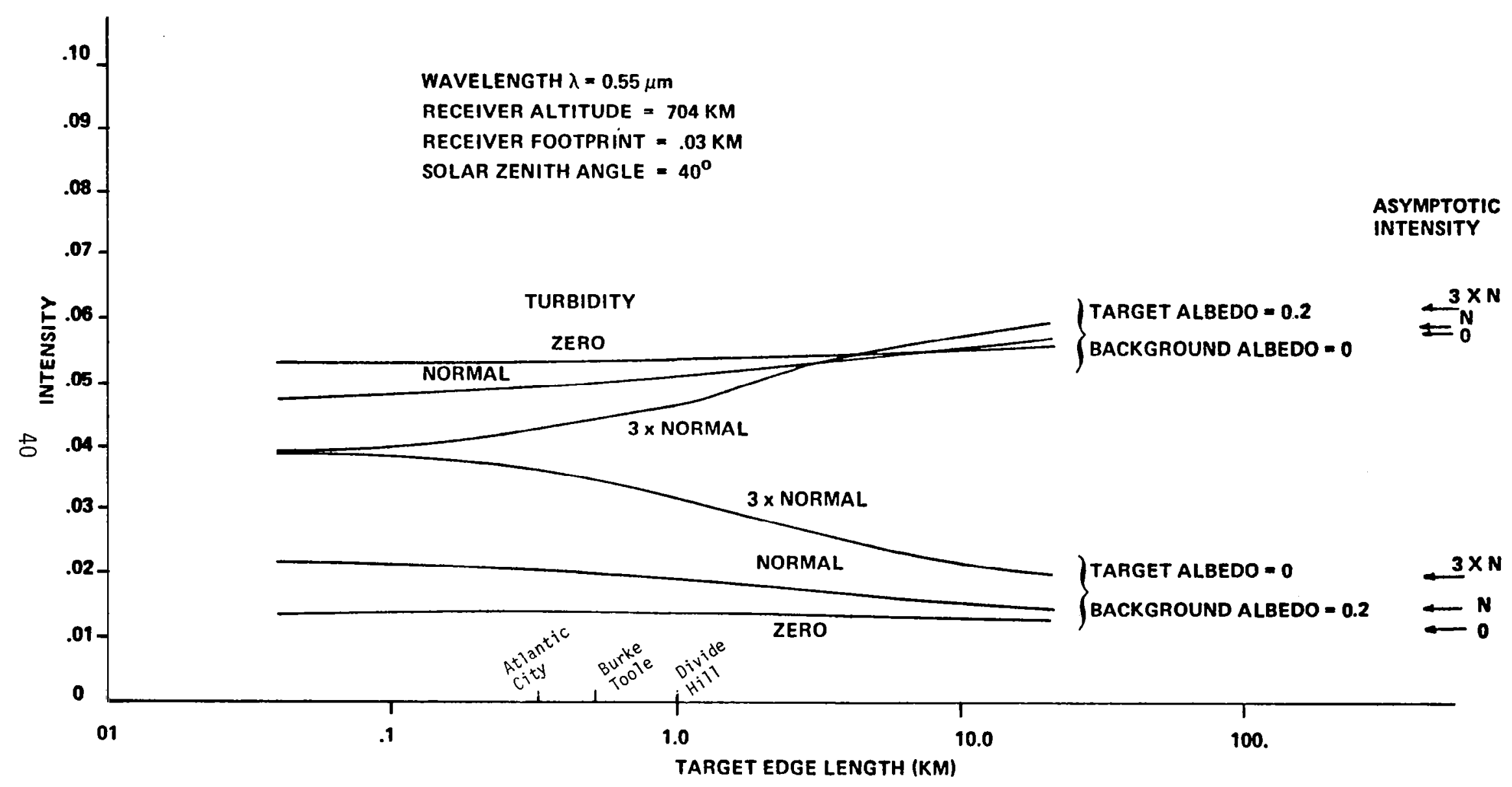

Figure 5-4. Intensity vs Target Square Edge Length (after Pearce(18)). 
$0.29 \mathrm{~N}$ to $1.48 \mathrm{~N}$. At the Salton Sea where the surrounding desert albedo is much higher than that of the San Diego 1 and surface, the water radiances take 3-6 pixels to become constant. These results are in reasonable agreement with the theoretical predictions, although the measured water radiances could well be enhanced by bottom reflectance and suspended matter in the near shore region making the measured change across the boundary slower than in ideal model conditions. It is virtually impossible to check the predicted adjacency effect out to large distances from the shore line since we cannot be sure of the homogeneity of the atmosphere, and, the ocean is not a Lambertian reflector.

The San Diego and Salton Sea data for MSS7 are shown in Figure 5-5. Raw data tapes were not readily available for these sites, so only radiances for aerosol contents greater than $0.75 \mathrm{~N}$ are shown, since our analysis of the inland sites showed the radiance values at these aerosol contents to be about the same on both the calibrated and the raw tapes. These radiance values are uncorrected for water vapor absorption, but as shown earlier for the inland sites, the scatter of points in the radiance-aerosol content relationship is not significantly affected by the water vapor correction. There is no obvious difference between the San Diego and Salton Sea data. This contrasts with the calculations of Pearce, which suggest that the Salton Sea radiance should be enhanced due to the high desert albedo $(0.5)$ by about $10 \%$.

Also shown in Figure 5-5 are the MSS7 radiances (also uncorrected for water vapor absorption) for the inland sites; these are generally slightly higher than for San Diego as more clearly demonstrated by the regression lines for each data set:

$$
\begin{aligned}
& \text { San Diego and Salton Sea: } \begin{aligned}
R & =.31+.33 \mathrm{~N} \\
r & =.48, \mathrm{~s}_{\mathrm{d}}=.12(21 \text { points) }
\end{aligned} \\
& \quad \mathrm{R}=.39+.38 \mathrm{~N} \\
& \mathrm{r}=.91, \mathrm{~s}_{\mathrm{d}}=.17 \text { (24 points) }
\end{aligned}
$$




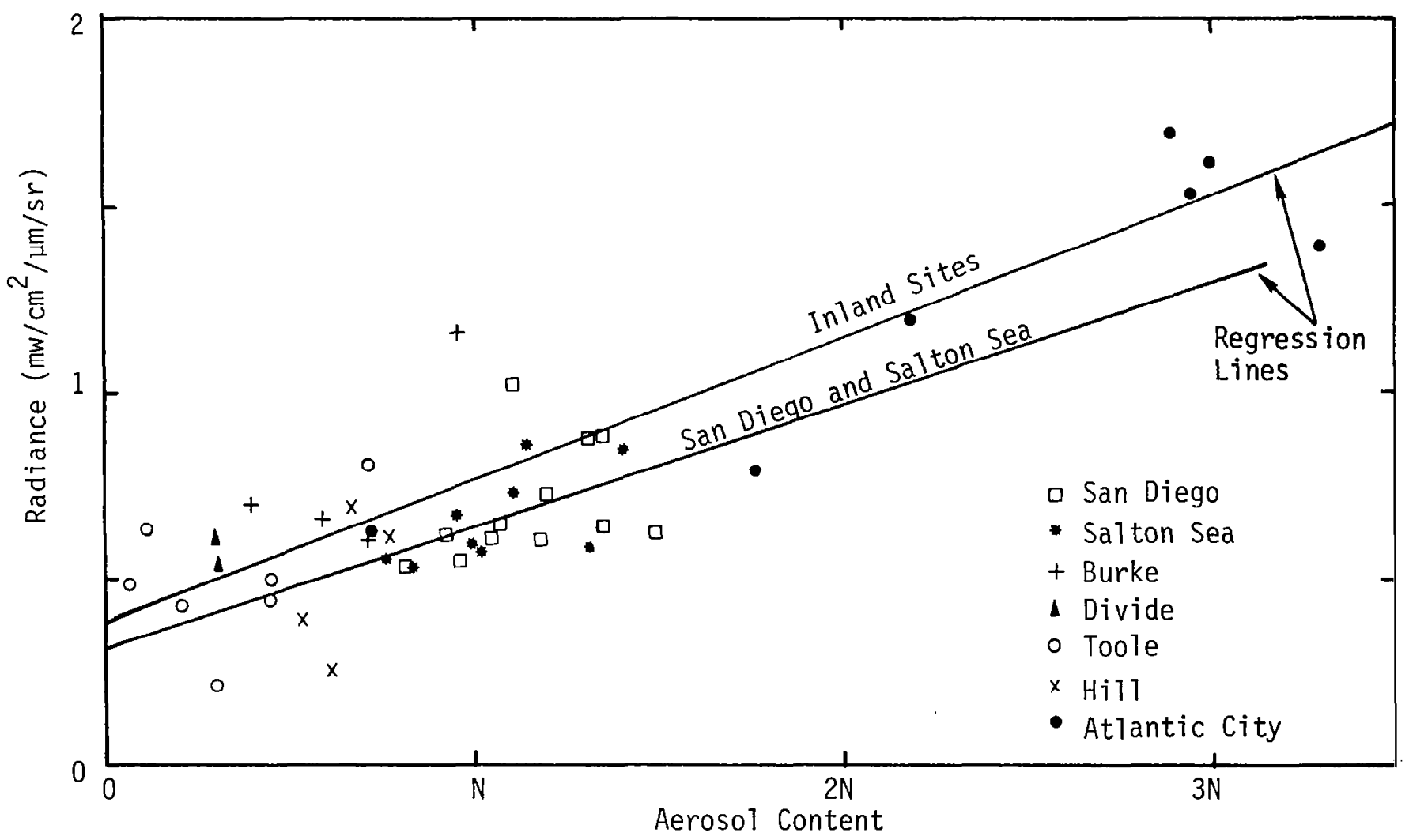

Figure 5-5. Radiance vs Aerosol Content for MSS7. 
The difference in the regression lines is in fair agreement with the theoretical predictions discussed above. An analysis of the inland data in Section 5.5, shows that the inland radiance values are on average $21 \%$ higher than would be predicted by the San Diego and Salton Sea regression line. The possibility that the higher inland radiances are due to water turbidity instead of, or in addition to, adjacency effects is also discussed in Section 5.5 .

\subsection{A Comparison of Inland and Ocean Landsat Data}

Table 5-4 shows the radiances measured at the inland sites for the water and surrounding land in comparison with the ocean radiances which would be predicted, for the measured inland aerosol contents, from the San Diego and Salton Sea regression 1 ine given in Equation 5-3. The radiance differences (referred to as RD from here on) between the observed inland water radiances and those predicted by the ocean data are assumed to be due to (a) adjacency effects at the inland sites, (b) inland water turbidity effects, (c) a difference in aerosol properties at the inland sites and the ocean, or (d) errors in the sunphotometer data.

The fractional RD (FRD) (i.e., the radiation difference expressed as a fraction of the predicted ocean radiancel for MSS6 and MSS7 are given as a function of aerosol content in Figures 5-6 and 5-7; MSS6 shows a clear tendency for the FRD to decrease with increasing $N$, which would be expected if the FRD is due to water turbidity effects, whereas the adjacency effect predicts an increase in FRD with $\mathrm{N}$. A decrease in FRD with $\mathrm{N}$ is not so obvious for MSS7, but certainly there is not an increase. Based on these plots, it appears that the RD can probably be attributed to water turbidity effects.

The FRD for MSS6 and MSS7 are also plotted against the MSS7 radiance of the surrounding land, which is approximately normalized by multiplying it by the cosine of the sun zenith angle, in Figures 5-8 and 5-9. The land radiances were obtained as an average, by eye, of the MSS7 radiances within about $1 \mathrm{~km}$ of each site. These values are assumed to be proportional to the land albedo, and can be used for both MSS6 and MSS7 to investigate the effect of the 1 and albedo on the FRD. The theory of the adjacency effect indicates that the FRD should increase with increasing albedo. The plots in Figures 5-8 and 5-9 show no correlation 
Table 5-4. Comparison of Inland and Ocean Radiances

\begin{tabular}{|c|c|c|c|c|c|c|c|c|c|c|c|c|c|c|}
\hline \multirow[b]{2}{*}{ Target } & \multirow[b]{2}{*}{ Date } & \multirow{2}{*}{$\begin{array}{l}\text { Aerosol } \\
\text { Content } \\
(\mathrm{N}) \\
\end{array}$} & \multicolumn{5}{|c|}{$\begin{array}{l}\text { MSS7 Radiance } \\
\left(\mathrm{mw} / \mathrm{cm}^{2} / \mu \mathrm{m} / \mathrm{sr}\right)\end{array}$} & \multicolumn{5}{|c|}{$\begin{array}{l}\text { MSS6 Radiance } \\
\left(\mathrm{mw} / \mathrm{cm}^{2} / \mu \mathrm{m} / \mathrm{sr}\right)\end{array}$} & \multirow{2}{*}{\multicolumn{2}{|c|}{$\begin{array}{c}\text { MSS7 } \\
\text { Land Radiance } \\
\times \cos 90 \\
\left(\mathrm{mw} / \mathrm{cm}^{2} / \mu \mathrm{m} / \mathrm{sr}\right)\end{array}$}} \\
\hline & & & $\begin{array}{l}\text { Inland } \\
\text { Water } \\
\end{array}$ & $\begin{array}{l}\text { Mean } \\
\text { Ocean } \\
\end{array}$ & $\begin{array}{r}\text { Inland } \\
\text {-0cean* } \\
\end{array}$ & \multicolumn{2}{|c|}{$\frac{\text { Inland-0cean }}{\text { Ocean }}$} & $\begin{array}{l}\text { Inland } \\
\text { Water }\end{array}$ & $\begin{array}{l}\text { Mean } \\
\text { Ocean }\end{array}$ & $\begin{array}{l}\text { Inland } \\
\text {-Ocean* }\end{array}$ & $\underline{\text { Inla }}$ & $\frac{\text { and-0cean }}{\text { Ocean } \star}$ & & \\
\hline \multirow[t]{2}{*}{$\begin{array}{l}\text { Atlantic City - } \\
\text { (Reservoir) } \\
\text { (4 pixels wide) }\end{array}$} & $\begin{array}{l}4-18-76 \\
6-12-76 \\
7-18-76 \\
8-22-76 \\
4-19-76 \\
8-23-76 \\
9-28-76\end{array}$ & $\begin{array}{r}3.29 \\
2.18 \\
1.76 \\
2.99 \\
2.89 \\
2.94 \\
.72\end{array}$ & $\begin{array}{l}1.40 \\
1.20 \\
.79 \\
1.62 \\
1.69 \\
1.53 \\
.62\end{array}$ & $\begin{array}{r}1.39 \\
1.03 \\
.89 \\
1.29 \\
1.26 \\
1.27 \\
.53\end{array}$ & $\begin{array}{r}.01 \\
.17 \\
-.10 \\
.33 \\
.43 \\
.26 \\
.09\end{array}$ & & $\begin{array}{r}.01 \\
.17 \\
. .11 \\
.17 \\
.34 \\
.18 \\
.17 \\
\end{array}$ & $\begin{array}{l}1.75 \\
1.50 \\
1.19 \\
2.03 \\
1.91 \\
1.93 \\
1.01\end{array}$ & $\begin{array}{l}2.15 \\
1.55 \\
1.32 \\
1.99 \\
1.93 \\
1.96 \\
.76\end{array}$ & $\begin{array}{r}-.40 \\
-.05 \\
-.13 \\
.04 \\
-.02 \\
-.03 \\
.25\end{array}$ & & $\begin{array}{r}-.19 \\
-.03 \\
-.10 \\
.02 \\
-.01 \\
-.02 \\
. .33 \\
\end{array}$ & & $\begin{array}{l}5.10 \\
9.07 \\
8.31 \\
6.13 \\
4.15 \\
5.79 \\
4.28 \\
\end{array}$ \\
\hline & & & & & & Mean & .13 & & & & Mean & .00 & Albedo & $n . .20+.35$ \\
\hline \multirow[t]{2}{*}{$\begin{array}{l}\text { Toole (Lake) o } \\
\text { ( } 5 \text { pixels wide) }\end{array}$} & $\begin{array}{l}6-04-76 \\
7-10-76 \\
7-28-76 \\
9-20-76 \\
7-22-77 \\
4-23-77 \\
5-11-77\end{array}$ & $\begin{array}{l}.72 \\
.44 \\
.44 \\
.30 \\
.20 \\
.11 \\
.06\end{array}$ & $\begin{array}{l}.81 \\
.45 \\
.50 \\
.22 \\
.43 \\
.64 \\
.48\end{array}$ & $\begin{array}{l}.55 \\
.46 \\
.46 \\
.41 \\
.38 \\
.35 \\
.33\end{array}$ & $\begin{array}{r}.26 \\
-.01 \\
.04 \\
-.19 \\
.05 \\
.29 \\
.15\end{array}$ & & $\begin{array}{r}.47 \\
-.02 \\
.08 \\
-.46 \\
.13 \\
.83 \\
.45 \\
\end{array}$ & $\begin{array}{l}1.18 \\
.73 \\
.80 \\
.77 \\
.83 \\
.97 \\
.87\end{array}$ & $\begin{array}{l}.76 \\
.61 \\
.61 \\
.54 \\
.48 \\
.43 \\
.41\end{array}$ & $\begin{array}{l}.42 \\
.12 \\
.19 \\
.23 \\
.35 \\
.54 \\
.46\end{array}$ & & $\begin{array}{r}.55 \\
.20 \\
.31 \\
.43 \\
.73 \\
.26 \\
1.12 \\
\end{array}$ & & $\begin{array}{l}6.00 \\
7.56 \\
6.22 \\
3.52 \\
5.62 \\
4.47 \\
5.34 \\
\end{array}$ \\
\hline & & & & & & Mean & .21 & & & & Mean & .66 & Albedo & $\sim .13+.23$ \\
\hline \multirow[t]{2}{*}{$\begin{array}{l}\text { Burke (River) }+ \\
(9 \text { pixels wide) }\end{array}$} & $\begin{array}{r}5-28-76 \\
7-21-76 \\
10-01-76 \\
6-28-77\end{array}$ & $\begin{array}{l}.58 \\
.95 \\
.72 \\
.39\end{array}$ & $\begin{array}{r}.66 \\
1.16 \\
.61 \\
.70\end{array}$ & $\begin{array}{l}.50 \\
.62 \\
.55 \\
.44\end{array}$ & $\begin{array}{l}.16 \\
.54 \\
.06 \\
.26\end{array}$ & & $\begin{array}{l}.32 \\
.37 \\
.11 \\
.59 \\
\end{array}$ & $\begin{array}{l}1.11 \\
1.74 \\
1.34 \\
1.49\end{array}$ & $\begin{array}{l}.69 \\
.89 \\
.76 \\
.58\end{array}$ & $\begin{array}{l}.42 \\
.85 \\
.58 \\
.91\end{array}$ & & $\begin{array}{r}.61 \\
.96 \\
.76 \\
1.57 \\
\end{array}$ & & $\begin{array}{l}6.83 \\
7.63 \\
2.64 \\
8.00 \\
\end{array}$ \\
\hline & & & & & & Mean & .47 & & & & Mean & .98 & Albedo & $2.10 \times .30$ \\
\hline \multirow[t]{2}{*}{$\begin{array}{l}\text { Divide (Lake) } \Delta \\
\text { (15 pixels wide) }\end{array}$} & $\begin{array}{l}3-09-76 \\
9-14-76\end{array}$ & $\begin{array}{l}.30 \\
.30\end{array}$ & $\begin{array}{l}.54 \\
.61\end{array}$ & $\begin{array}{l}.41 \\
.41\end{array}$ & $\begin{array}{l}.13 \\
.20\end{array}$ & & $\begin{array}{r}.32 \\
.49 \\
\end{array}$ & $\begin{array}{r}1.07 \\
.88\end{array}$ & $\begin{array}{l}.54 \\
.54\end{array}$ & $\begin{array}{l}.53 \\
.34\end{array}$ & & $\begin{array}{l}.98 \\
.63 \\
\end{array}$ & & $\begin{array}{l}4.70 \\
3.43 \\
\end{array}$ \\
\hline & & & & & & Mean & .41 & & & & Mean & .81 & Albedo & $\sim .15$ \\
\hline \multirow[t]{2}{*}{$\begin{array}{l}\text { Hill (River) } x \\
(30 \text { pixels wide) }\end{array}$} & $\begin{array}{r}5-16-76 \\
9-19-76 \\
10-07-76 \\
8-08-77\end{array}$ & $\begin{array}{l}.67 \\
.62 \\
.53 \\
.77\end{array}$ & $\begin{array}{l}.70 \\
.31 \\
.38 \\
.62\end{array}$ & $\begin{array}{l}.53 \\
.52 \\
.49 \\
.56\end{array}$ & $\begin{array}{r}.17 \\
-.21 \\
-.11 \\
.06\end{array}$ & & $\begin{array}{r}.32 \\
-.40 \\
-.22 \\
.11 \\
\end{array}$ & $\begin{array}{r}1.05 \\
.77 \\
.91 \\
1.10\end{array}$ & $\begin{array}{l}.74 \\
.71 \\
.66 \\
.79\end{array}$ & $\begin{array}{l}.31 \\
.06 \\
.25 \\
.31\end{array}$ & & $\begin{array}{l}.42 \\
.08 \\
.38 \\
.39 \\
\end{array}$ & & $\begin{array}{l}6.63 \\
3.32 \\
2.77 \\
5.36 \\
\end{array}$ \\
\hline & & & & & & Mean & -.05 & & & & Mean & .32 & Albedo & $2.10 \rightarrow .25$ \\
\hline $\begin{array}{l}\star(\mathrm{RD}) \\
\star \star(\mathrm{FRD})\end{array}$ & & & & \multicolumn{2}{|c|}{ Mean (a) } & ites) & .21 & & & lean (all & ites) &. .47 & & \\
\hline
\end{tabular}




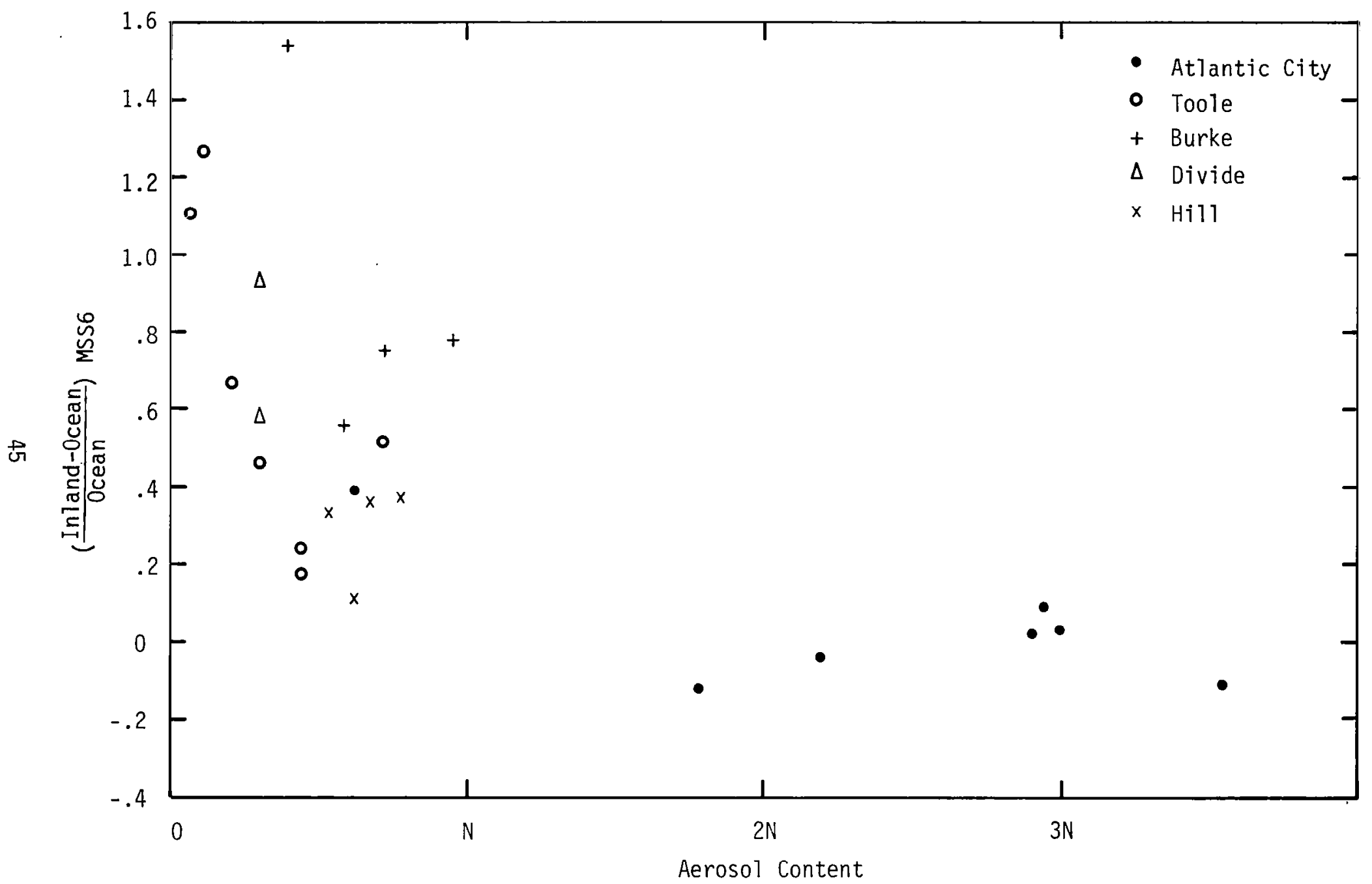

Figure 5-6. Fractional Radiance Difference as Function of Aerosol Content for MSS6. 


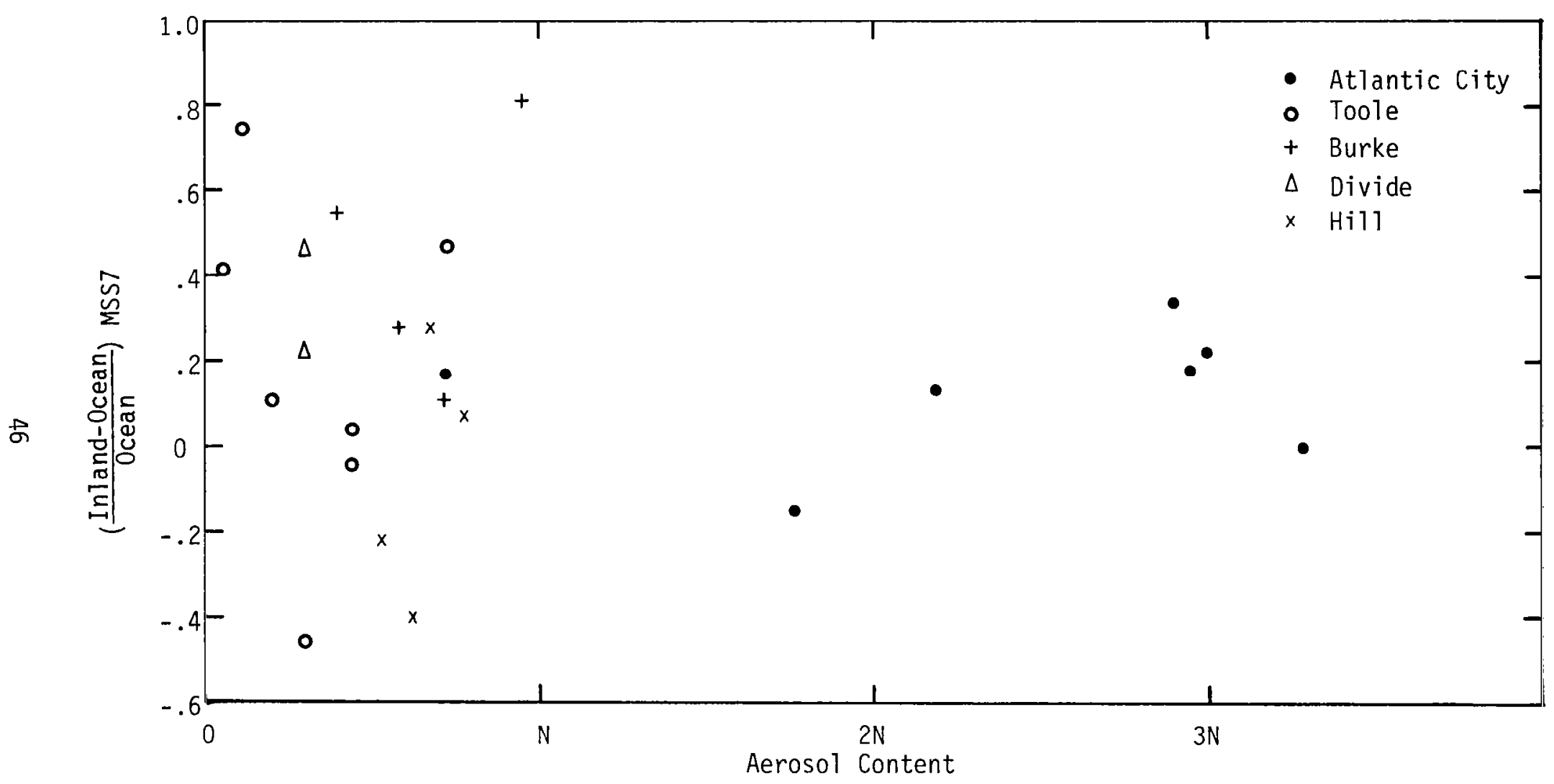

Figure 5-7. Fractional Radiance Difference as Function of Aerosol Content for MSS7. 


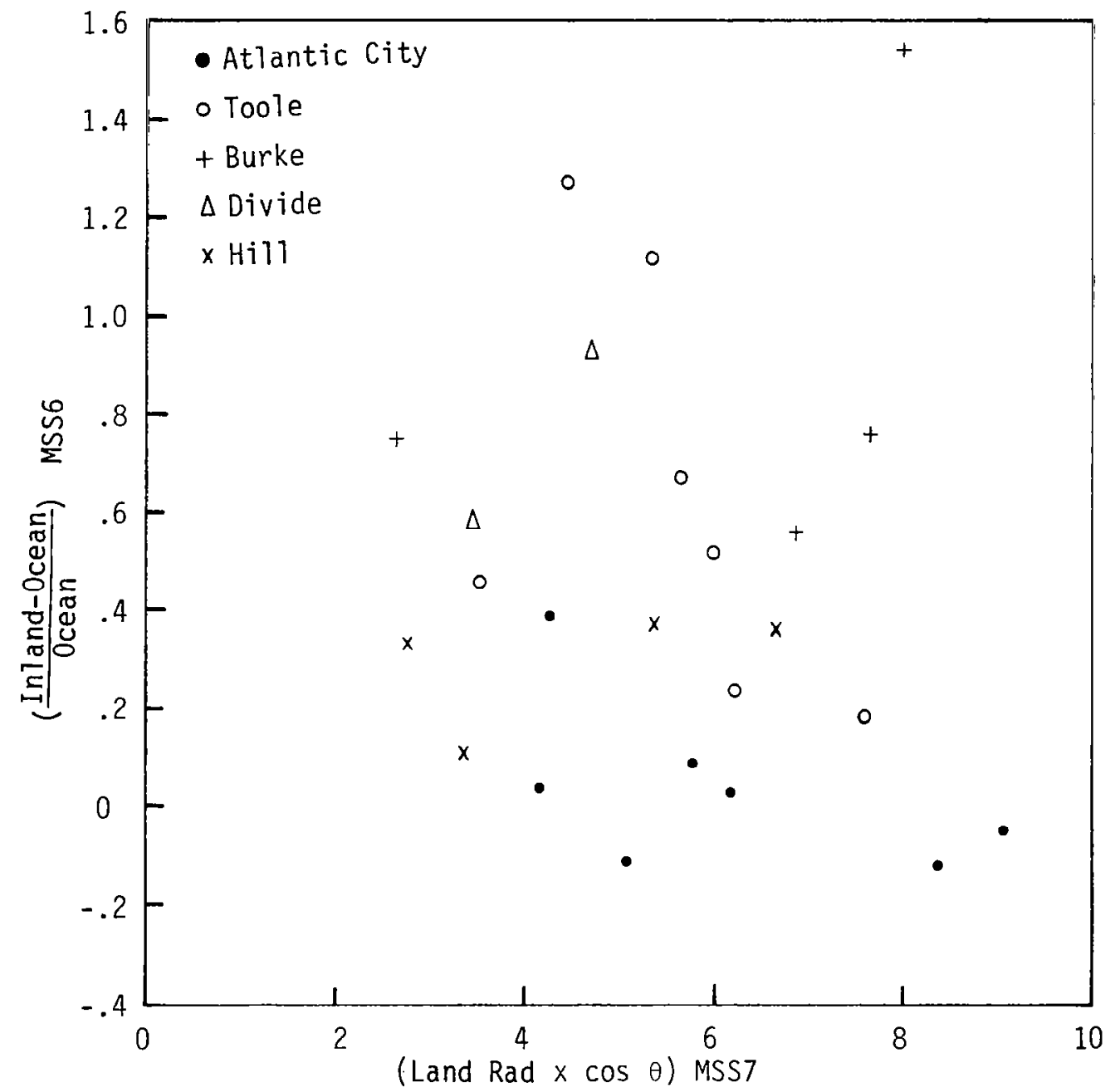

Figure 5-8. Fractional Radiance Difference as a Function of Surrounding Land Radiance for MSS6. 


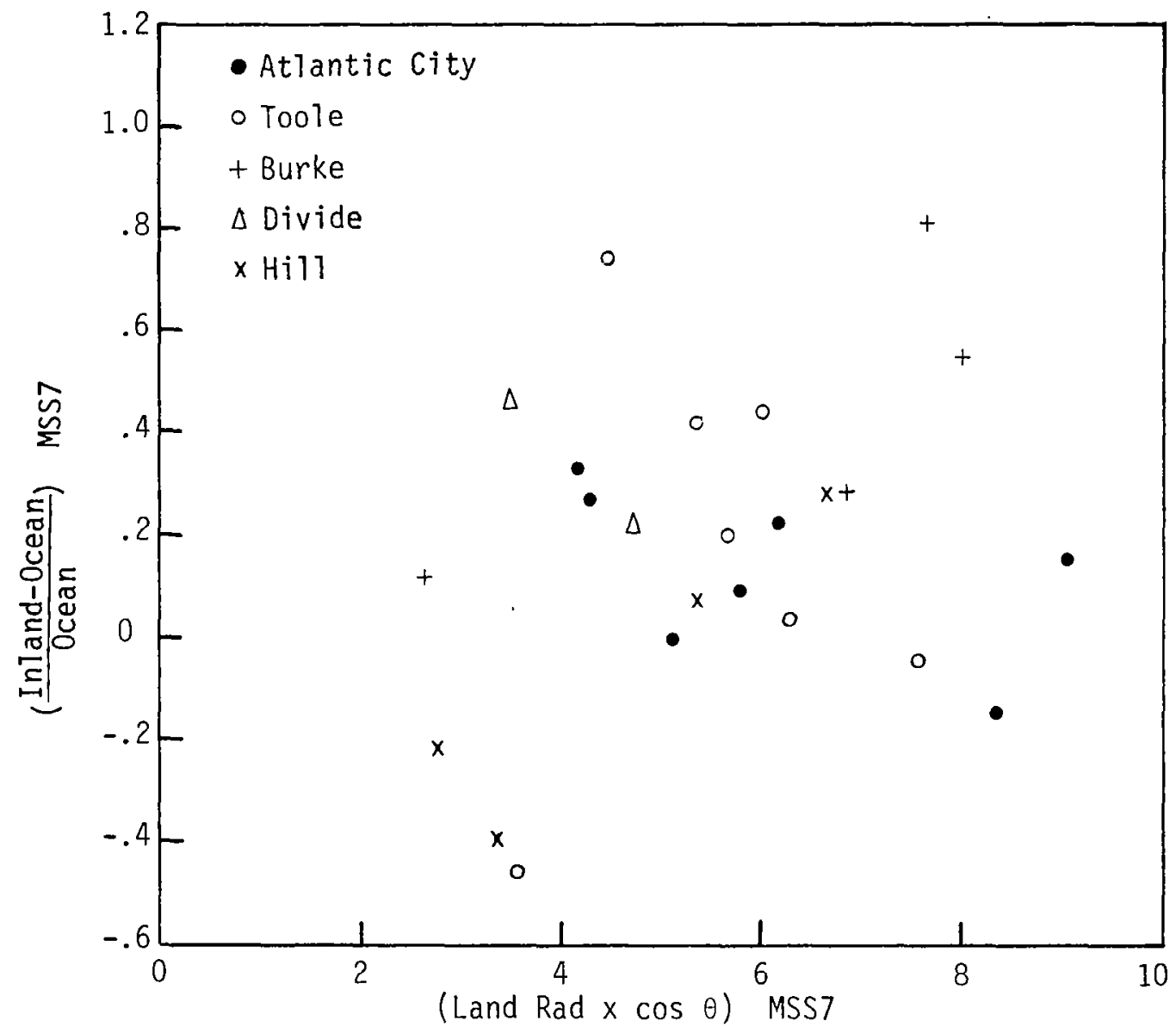

Figure 5-9. Fractional Radiance Distance as a Function of Surrounding Land Radiance for MSS7. 
between $F R D$ and the 1 and radiance, suggesting that the adjacency effect is not responsible for the FRD.

The adjacency effect, according to theory, should be more apparent over a smaller target. In this study, the iniand bodies of water are of varying shapes, so that the target area of importance in the adjacency effect is difficult to define. Probably the smallest dimension of the target is most important, so the area of the target is taken as the square of the smallest dimension for comparison. Figure 5-10 shows the FRD as a function of the relative area of the water body; there is no clear correlation, with the smallest and largest water bodies showing similar values of FRD.

A correlation between the FRD in MSS6 and MSS7 is apparent in Figure 5-11. Since both channels show no correlation between the FRD and 1 and radiance or aerosol content, then it is probable that the correlation shown in Figure 5-11 is due to water turbidity effects, aerosol properties, or errors in the value of $\mathrm{N}$, all of which could produce similar effects on the FRD in each channel. If the aerosol properties were mainly responsible for the FRD in each channel, and hence the correlation between the channels, then the radiance intercept of the regression 1 ines for the inland sites should be close to that for the oceans since $\mathrm{N}=0$ represents a pure molecular atmosphere. However, al though Equations 5-3 and 5-4 show the MSS7 intercepts to be similar, the MSS6 values are quite different as shown in the regression lines:

$$
\begin{array}{ll}
\text { San Diego: } & \mathrm{R}=.37+.54 \mathrm{~N} \\
& \mathrm{r}=.93 \mathrm{~s}_{\mathrm{d}}=.07 \text { (22 points) } \\
\text { Inland Sites: } & \mathrm{R}=.91+.32 \mathrm{~N} \\
& \mathrm{r}=.83 \mathrm{~s}_{\mathrm{d}}=.22(24 \text { points })
\end{array}
$$

Thus, it appears that the aerosol properties do not significantly contribute to the FRD.

Errors in $\mathrm{N}$ can occur due to instrument errors in the sunphotometer as discussed earlier, or they could be due to inhomogeneities in the atmosphere since the sunphotometer was never directly adjacent to the inland bodies of water. The Atlantic City observation was about $2 \mathrm{~km}$ from the reservoir, the 


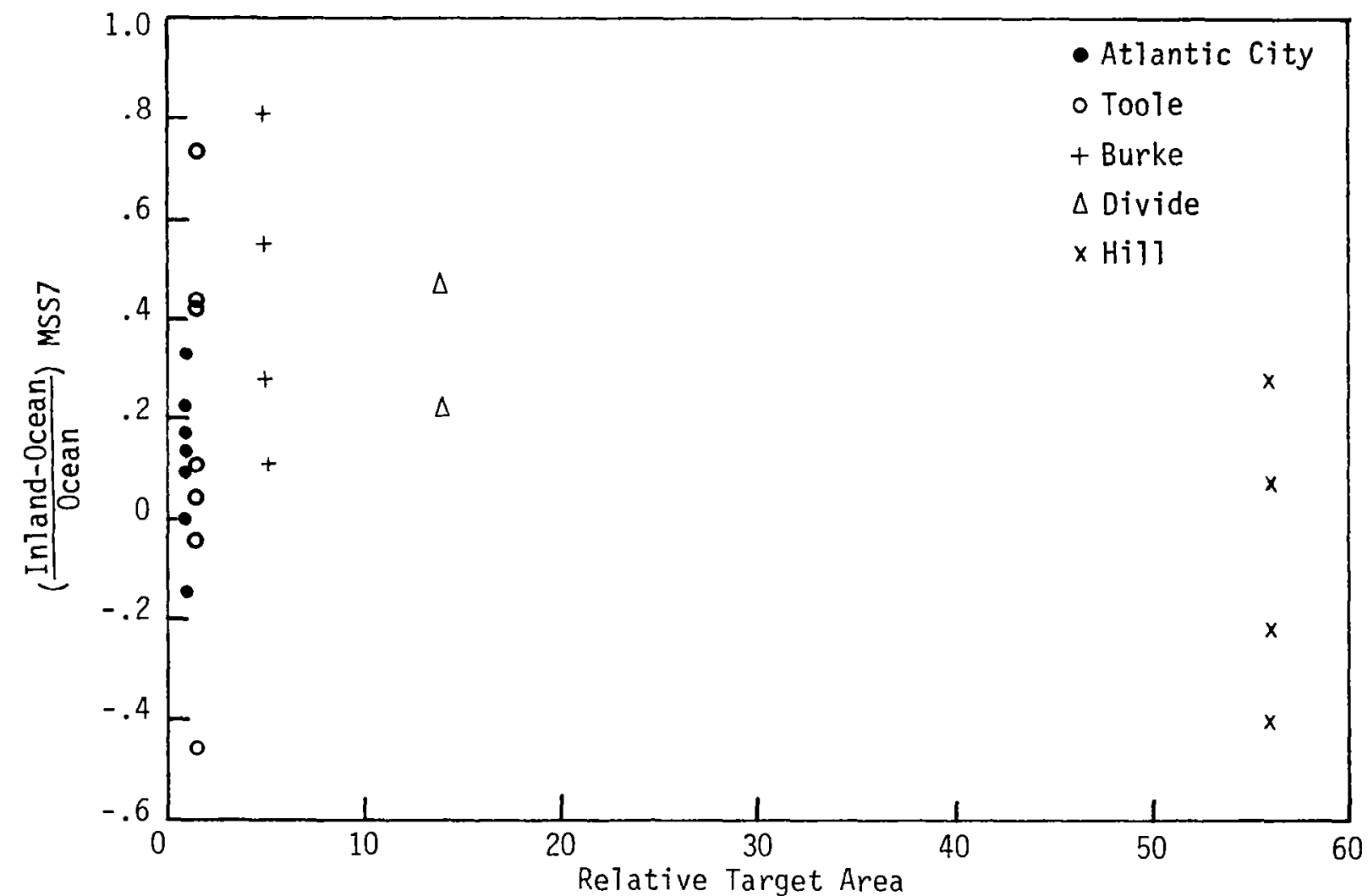

Figure 5-10. Fractional Radiance Difference in MSS7 vs Relative Area of Inland Sites. 


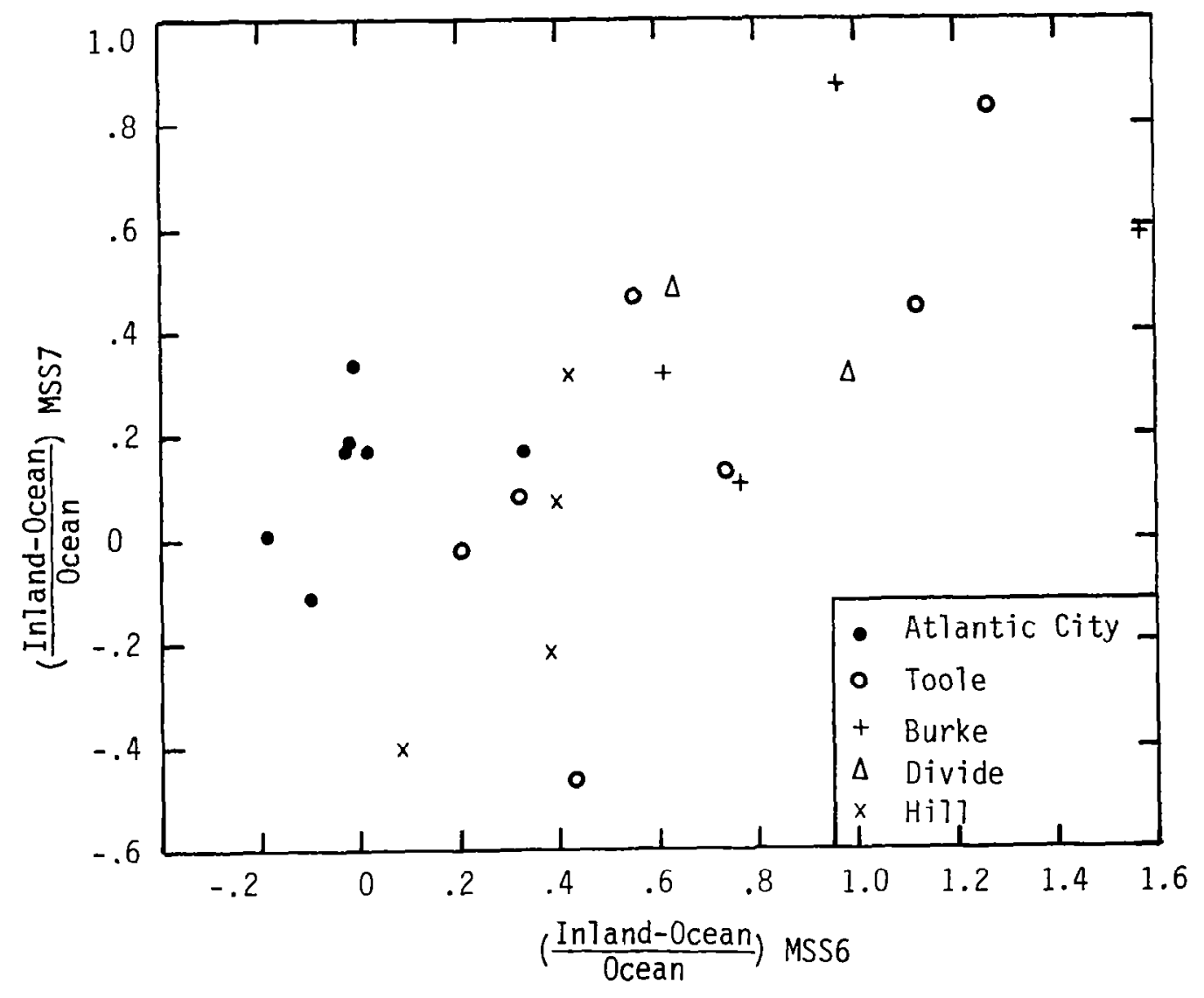

Figure 5-11. Fractional Radiance Difference in MSS7 vs Fractional Radiance Difference in MSS6. 
Toole observer was about $3 \mathrm{~km}$ from the lake, the Burke observer was about $3 \mathrm{~km}$ from the river, the Divide observer was about $500 \mathrm{~m}$ from the lake, and the Hill observer was about $8 \mathrm{~km}$ from the river. It would certainly have been desirable to have the observations made closer to the target, but since the data reported here are always for clear sky conditions, it is believed that atmospheric inhomogeneities were at a minimum. It is difficult to separate the contributions of errors in $N$ and of water turbidity to the correlation between the channels in Figure 5-11, but a similar plot of the fractional radiance differences from the regression 1 ine (Equation 5-3) for the San Diego and Salton Sea data, shown in Figure 5-12, can help. For these observations, the same sunphotometer, known to be stable, was always used at both sites by a trained observer who made careful measurements only in the best conditions, $i . e$. , with clear skies and a visually homogeneous atmosphere, and directly at the water's edge. Thus, little error is expected in the value of $\mathrm{N}$ at these sites. However, there is still a correlation between the radiance differences in each channel. This could be due to variation in the aerosol properties but since the correlation is particularly strong for the Salton Sea data where water turbidity has been observed in the Landsat imagery on occasion, it appears that water turbidity is most likely responsible for the correlation at these two sites. It is not unreasonable to also attribute the correlation at the inland sites to water turbidity, which is certainly often very apparent in the imagery.

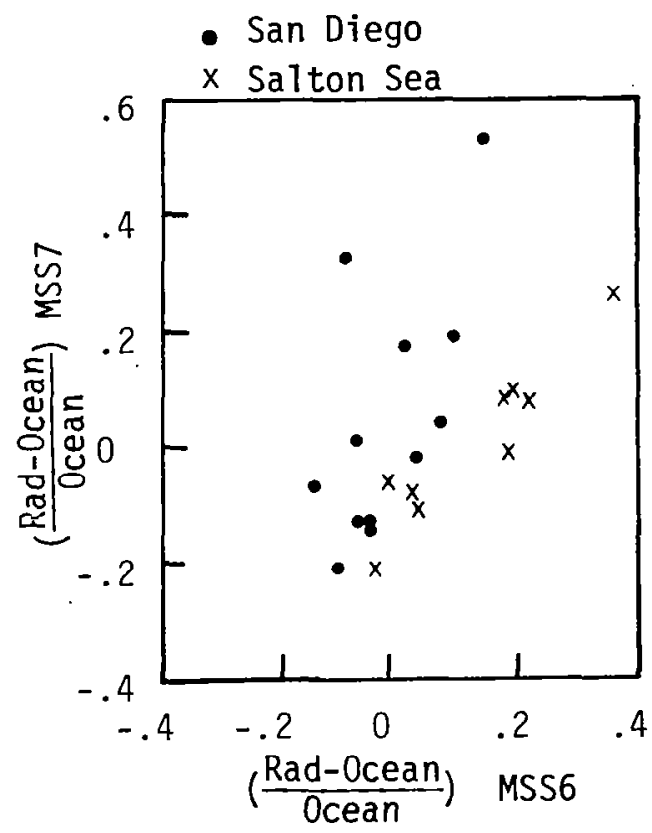

Figure 5-12. Fractional Radiance Differences in MSS7 vs Fractional Differences in MSS6 at San Diego and Salton Sea. 
It is concluded, then, that the apparent enhanced radiances, relative to ocean values, observed over these inland bodies of water are probably mostly due to water turbidity effects; uncertainties in the value of the measured aerosol optical thickness may contribute a little. No evidence of a significant adjacency effect could be found with the data available.

\subsection{Estimation of the Aerosol Content from Radiance Measurements}

The purpose of this investigation is to evaluate the usefulness of using MSS7 radiance measurements over inland bodies of water to determine the atmospheric aerosol content. It is apparent from the discussions in the preceding sections that a relationship similar to that found over the ocean does exist, but with more scatter of the data. It is probable that most of the scatter is due to water turbidity effects with perhaps some contribution from errors in the measured aerosol content.

The error in determining the aerosol content ( $N$ ) from a MSS7 radiance measurement $(R)$ may be estimated by considering the regression 1 ine of $N$ on $R$ at the inl and sites:

$$
\begin{aligned}
& N=-0.68+2.21 R \\
& r=.91, i . e, s_{d}=.42
\end{aligned}
$$

A lower (optimistic) limit to the error is given by assuming that all the scatter of data in Figure 5-1 is due to errors only in the measurements of $\mathrm{N}$ and $R$. In this case, the standard deviation $\sigma(N)$ of $N$ is given by the product of the slope of Equation 5-7 and the NER (for a 9-pixel target, and modified by a sun correction factor of 0.85 ) in Table $5-3$, so that:

$$
\sigma(N)=0.11 \mathrm{~N}
$$


An upper (and more likely) limit is obtained if the scatter of data is assumed to be due to contributions from all the error sources discussed, so that the standard deviation of $\mathrm{N}$ is given by the standard error of estimate $\mathrm{s}_{d}$ of the regression line, i.e.,

$$
\sigma(N)=.42 N
$$

For comparison, the MSS6 ocean data at San Diego has a regression 1 ine given by

$$
\begin{aligned}
& N=-0.48+1.60 R \\
& r=.93, s_{d}=.12
\end{aligned}
$$

From Table 5-3, for a 40-pixel target, it is found that the error 1 imits for the MSS6 ocean data are:

$$
.01 \leq \sigma(N) \leq .12 N
$$

showing the better accuracy of MSS6 measurements (with a smaller NER) over the ocean, where the error sources are at a minimum, and a larger target area can be used.

The upper error limit for MSS7 at the inland sites would be reduced if the relationship were obtained from a large set of data for one site, thus minimizing the uncertainties in the measurement of $\mathrm{N}$, and perhaps reducing the water turbidity effects. However, the errors at inland sites would still be significantly greater than over the ocean, perhaps precluding the use of inland sites for measurements at a given time and $p 1$ ace. Inland bodies of water would be better used for determining average values (thus reducing the error) of the aerosol content; this could be a time average at a given site, or an area average at a given time if several sites are close together. 
It is concluded that, based on the 1 imited data for five inland bodies of water, a linear relationship exists between the radiance measured by the Landsat 2 MSS7 and the aerosol content above the water. This relationship can be used to estimate the aerosol content with a standard deviation of $0.42 \mathrm{~N}$. This error could probably be reduced by obtaining data at a single site with just one sunphotometer, rather than' using several sites and several sunphotometers. However, the relationships would probably then be found to vary with each site, depending on the type of waterturbidity and type of aerosol, so probably the result found in this investigation is preferred for general application.

The uncertainty in the aerosol content measured over an inland body of water is about three times greater than that found over the ocean for MSS6. Analysis of the data for MSS6 and MSS7 suggests that the larger uncertainty is mostly due to water turbidity, with little contribution from the adjacency effect. The water turbidity effects could be reduced by making narrow-band observations around $1 \mathrm{\mu m}$ where the radiation penetrates water to only about $3 \mathrm{~cm}$. However, the atmospheric aerosols scatter less at this longer wavelength so that the sensitivity of the technique would be reduced. In addition, there is presently no satellite sensor operating at this wavelength with a small enough spatial resolution to use the small inland bodies of water as targets.

It appears that the relationship found in this investigation would best be applied to determining an average aerosol content over a period of time at a given target, or an area average at a given time over several targets close together; the averaging could reduce the uncertainty in the measured aerosol content to a useful level.

The conclusion that the adjacency effect does not contribute significantly, in contrast to theoretical calculations, to the upwelling radiance over small bodies of inland water is important. There is concern for adjacency effects in scene classification for the Landsat thematic mapper, and it would be desirable to have experimental verification of the theoretical models that have been developed. 
It is reconmended that the adjacency effect be investigated experimentally by conducting a study, similar to this investigation, using 01 igotrophic lakes as targets, thus eliminating water turbidity effects, with ground-truth measurements of the optical thickness being made directly adjacent to the lakes. Such a program could provide input for modifying the theory of adjacency effects, and perhaps for determining an empirical correction, if necessary, for adjacency effects. 
7. REFERENCES

1. M. Griggs, Determination of Aerosol Content in the Atmosphere from Landsat Data. NASA CR-155788, 1978 .

2. P. Koepke and M. Quenzel, Turbidity of the Atmosphere Determined from Satellite Calculation of Optimum Viewing Geometry, $\underline{\text { J }}$ Geophys. Res. 34 , $7847(1979)$.

3. C.C. Norton et al., A Model for Calculating Desert Aerosol Turbidity Over

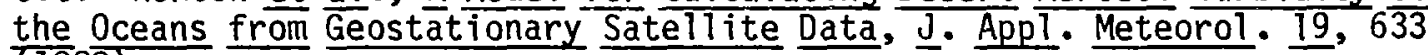
(7980)

4. M. Griggs, Measurements of Atmospheric Aerosol Optical Thickness over Water Using ERTS-1 Data, J. Air Poll. Contr. Assoc. 25, 622 (1975).

5. M. Griggs, Satellite Observations of Atmospheric Aerosols during the EOMET Cruise --- Simultaneous Shipborne Photometric Electro-0ptical Meteorology of Atmospheric Marine Boundary Layer, J. Atmos. Sci. $\underline{36}$, $696(1979)$.

6. L. El terman, "Atmospheric Optics," Handbook on Geophysics and Space Environments, S. Valley, Ed. McGraw-Hil1 7-1 to 7-2 (1965).

7. M.L. Wright, E.K. Proctor, L.S. Gasiorek and E.M. Liston, A Preliminary Study of Air Pollution Measurement by Active Remote-Sensing Techniques, $\overline{\text { NASA }} \mathrm{CR}-1 \overline{327} 2 \overline{4}(1975)$.

8. J.F. Potter and M.A. Mendlowitz, On the Determination of Haze Levels from Landsat Data, 10th Int. Symp. Rem. Sens. Environ., Ann Arbor (0ctober 1975).

9. E.H. Rogers, Study to Demonstrate the Feasibility of and Determine the Optimum Method for Remote Haze Monitoring by Satel1 ite, NASA CR-1424 $\overline{12}$, (1974).

10. P.N. S1ater, "MRS 'Proof-of-Concept' Study on Atmospheric Corrections," ORI, Inc. Rpt. No. TR 1653, NASA CR-166664, 1979.

11. T.A. Hariharan, Atmospheric Turbidity from Polarization of Outgoing Visible Radiation, Pure and Appl. Geophys. $86,198(1971)$.

12. J.C. Barnes, C.J. Bowley and H.K. Burke, "Evaluation of the Capabilities of Satellite Imagery for Monitoring Regional Air Pollution Episodes," NASA CR-159107, 1979.

13. J.V. Dave, A Modified Fourier Transform Method for Multiple Scattering Calculations in a Plane Parallel Mie Atmosphere, Appl. Optics 9, 1457, 1888 , and $267 \overline{3}(1970)$.

14. D.E. Pitts, W.E. McAllum, A.E. Dillinger "The Effect of Atmospheric Water Vapor on Automatic Classification of ERTS Data. Ninth Remote Sensing Symposium in Ann Arbor, Michigan, Aprit 1974. 
15. E.C. Flowers, R. A. McCormick and K.R. Kurtis, Atmospheric Turbidity over the United States, 1961-1966, J. App. Meteorol. 8 955 (1969).

16. Science Applications, Inc., "Tiros-N AVHRR Data for Measurements of Atmospheric Aerosols," Report (N0AA Contract M0-A01-78-00-4092), May T980.

17. R.E. Turner, "Atmospheric Effects in Multispectral Remote Sensing Data." NASA CR -141863, 1975 .

18. W.A. Peace, "A Study of the Effects of the Atmosphere on Thematic Mapper Observations."

19. J. Otterman and R.S. Fraser, Adjacency Effects on Imaging by Surface Reflection and Atmospheric Scattering - Cross Radiance to Zenith - for Satellite Multi spectral Photography. App. Opt. 18, 2852 (1979).

20. M. Gigs, "Determination of Aerosol Content in the Atmosphere from ERTS-1 Data." NASA CR-137441, 1973.

58 


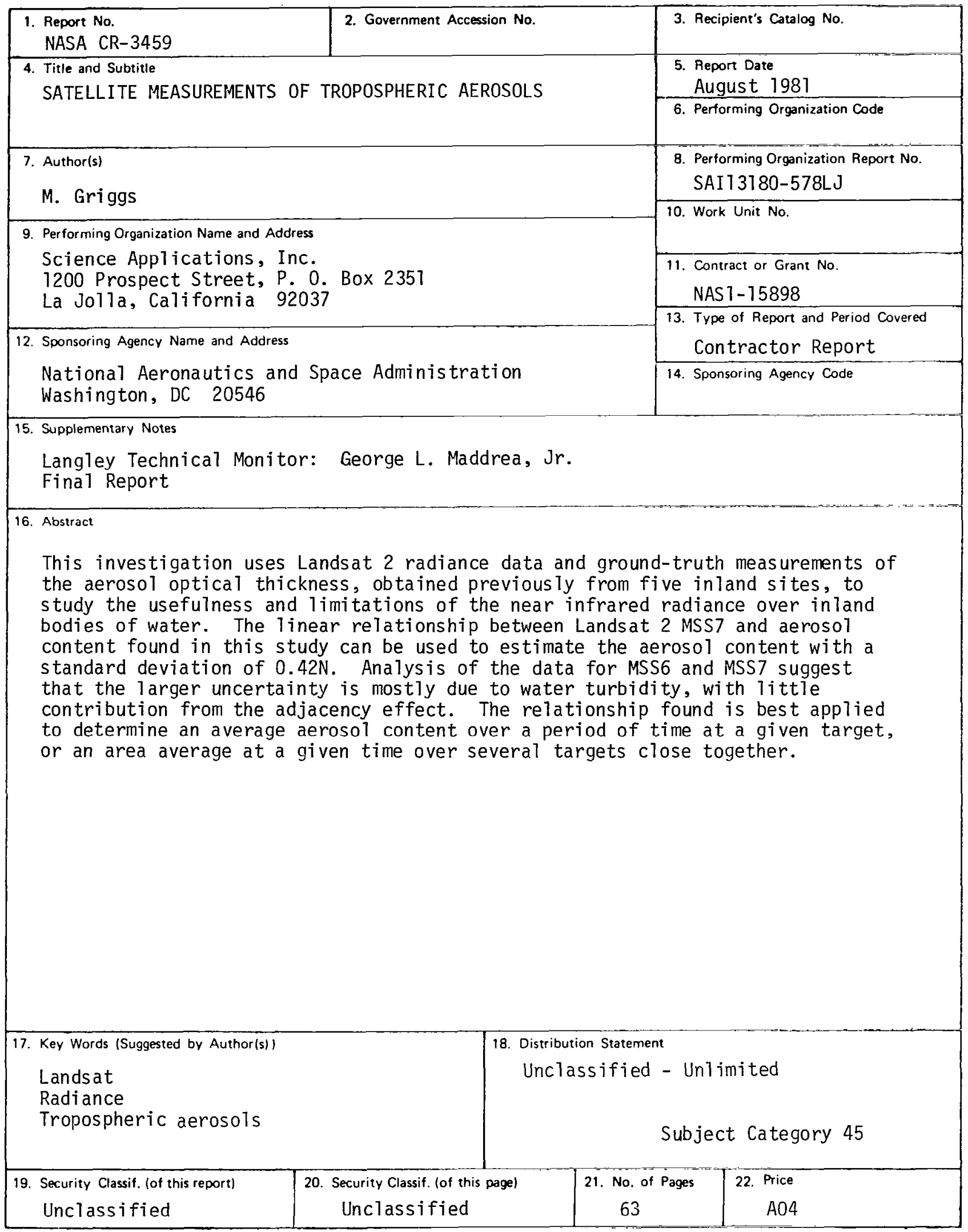

For sale by the National Technical Information Service, Springtield. Virginia 22161 